Please do not remove this page

RMIT

UNIVERSITY

\title{
Robust and Tunable Hybrid Hydrogels from Photo-Cross-Linked Soy Protein Isolate and Regenerated Silk Fibroin
}

Dorishetty, Pramod; Balu, Rajkamal; Sreekumar, Anjitha; de Campo, Liliana; Mata, Jitendra; Choudhury, Namita; Dutta, Naba

https://researchrepository.rmit.edu.au/esploro/outputs/9921860936201341/filesAndLinks?institution=61RMIT_INST\&index=null

Dorishetty, P., Balu, R., Sreekumar, A., de Campo, L., Mata, J., Choudhury, N., \& Dutta, N. (2019). Robust and Tunable Hybrid Hydrogels from Photo-Cross-Linked Soy Protein Isolate and Regenerated Silk Fibroin. ACS Sustainable Chemistry and Engineering, 7(10), 9257-9271.

https://doi.org/10.1021/acssuschemeng.9b00147

Document Version: Accepted Manuscript

Published Version: https://doi.org/10.1021/acssuschemeng.9b00147

Repository homepage: https://researchrepository.rmit.edu.au

(c) 2019 American Chemical Society

Downloaded On 2023/04/26 12:25:44 +1000 


\section{Robust and Tunable Hybrid Hydrogels from Photocrosslinked Soy Protein Isolate and Regenerated Silk Fibroin}

Pramod Dorishetty, ${ }^{\dagger}$ Rajkamal Balu, ${ }^{\dagger}$ Anjitha Sreekumar, ${ }^{\dagger}$ Liliana de Campo, ${ }^{\ddagger}$

Jitendra P. Mata, ${ }^{\neq}$Namita Roy Choudhury, $*,+\neq$ and Naba K. Dutta*,†,

${ }^{\dagger}$ Chemical and Environmental Engineering, School of Engineering, RMIT University, Melbourne, Victoria 3000, Australia.

${ }^{*}$ School of Chemical Engineering, University of Adelaide, Adelaide, South Australia 5005, Australia.

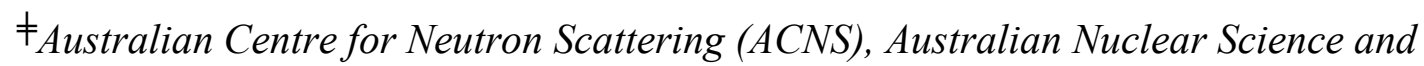
Technology Organisation (ANSTO), Lucas Heights, New South Wales 2232, Australia.

*Corresponding author E-mail: naba.dutta@rmit.edu.au; namita.choudhury@rmit.edu.au 


\section{ABSTRACT}

Soy protein isolate (SPI), a plant derived protein is emerging as a potential material for biomedical applications. Herein we report the development and structure-property relationship of photocrosslinked SPI and SPI/silk fibroin (SF) hybrid hydrogels for the first time. The pristine SPI hydrogels were crosslinked at two different structural configurations (i.e. at $\mathrm{pH} 7$ and 12), and SPI/SF hybrid hydrogels were co-crosslinked at $\mathrm{pH} 7$ in three different weight ratios (3:1, 1:1 and 1:3). The fabricated hydrogels were characterized using electron microscopy, X-ray diffraction, Raman and infrared spectroscopy, thermal analysis, small and ultra-small angle neutron scattering, rheology, water uptake and in vitro degradation studies. The equilibrium water swollen SPI hydrogel photocrosslinked at $\mathrm{pH} 7$ exhibited a particulate microstructure, controlled degradation in phosphate buffered saline, and a shear storage modulus of $\sim 7.7 \mathrm{kPa}$, which is in the range of human lumbar nucleus pulposus, and significantly higher than soy hydrogels reported by thermal treatment, pressure treatment, saltinduced cold-setting and enzymatic crosslinking. Conversely, the SPI hydrogel photocrosslinked at $\mathrm{pH} 12$ exhibited ordered porous microstructure, higher water uptake of $\sim 1946 \%$, and poor water-resistant and mechanical properties. Increase in SF content of the crosslinked SPI/SF hybrid hydrogels demonstrated improved porosity, swelling, molecular chain mobility, elastic and water-resistant properties. An in-depth understanding of the effect of $\mathrm{pH}$ and composition on the hierarchical structure and physicochemical properties of the fabricated hydrogels was established. Moreover, the SPI and SPI/SF hybrid inks used for photocrosslinking exhibited flow properties suitable for printing tissue engineering applications. The presented results contribute to a facile fabrication and fundamental understanding of the structure-property relationship of SPI-based hybrid hydrogels.

Keywords: Soy protein isolate, Silk fibroin, Photocrosslinked hydrogels, Structure-property relationship, Hierarchical structure, Physicochemical property 


\section{INTRODUCTION}

Protein-based hydrogels are highly water absorbing three-dimensional (3D) network of protein molecules being held together by crosslinks between the constituents, and are emerging as a new class of smart and responsive soft materials. ${ }^{1}$ Among proteins of natural origin, soy protein isolated from soybean and widely used in the food industry, has attracted significant interest in recent years for biomedical applications due to its abundance in nature, low cost, ease of processability, biocompatibility, biodegradability, inherent cell adhesion and growth mediation properties. ${ }^{2}$ Soy protein isolate (SPI) is a highly refined form of soy protein with a minimum protein content of $90 \%$ on a moisture-free basis, and has a complex molten globule structure with two major globulins, namely glycinin (11S with molecular weight, $\mathrm{M}_{\mathrm{w}}$ of $360 \mathrm{kDa}$ ) and $\beta$-conglycinin (7S with $\mathrm{M}_{\mathrm{w}}$ of $175 \mathrm{kDa}$ ). ${ }^{3}$ The molecular structure and solubility of SPI is sensitive to $\mathrm{pH}$, where SPI have been reported to show increased solubility (up to 2.5 -fold) at pH 12 compared to $\mathrm{pH} 7 .{ }^{3}$ Several methods including thermal treatment, ${ }^{4}$ pressure treatment, ${ }^{5}$ and cold-set salt-induced gelling ${ }^{6}$ have been reported for fabrication of SPI films and physical gels. However, SPI physical hydrogels developed using such methods exhibit poor mechanical and water-resistance properties, limiting their applications in the field of biomedical engineering including tissue engineering and drug delivery. ${ }^{5-7}$ Enzymatic and chemical crosslinking of SPI using agents such as transglutaminase,${ }^{8}$ epichlorohydrin, ${ }^{9}$ glutaraldehyde, ${ }^{10}$ and genipin ${ }^{11}$ have been reported to improve the physical properties of SPI hydrogels. Moreover, a few attempts have been made recently to fabricate SPI-based composite (SPIpolysaccharide, ${ }^{12}$ and SPI-ceramic ${ }^{13}$ ), and hybrid (SPI-synthetic polymer ${ }^{14}$ ) hydrogels with improved mechanical properties. However, the reported hydrogels suffer from long fabrication/gelation time and/or poor mechanical properties which are still inadequate for many targeted tissue engineering applications, such as human lumbar nucleus pulposus (center part of intervertebral disc), which has a shear dynamic modulus in the range of 7.4 to $19.8 \mathrm{KPa}$, and 
confined compression modulus in the range of 0.5 to $1.3 \mathrm{MPa} .{ }^{15}$ Moreover, the existing literature gap associated with fabrication of SPI-based hydrogels include lack of a fast and facile fabrication method for chemically crosslinking SPI that can be extended to co-crosslink SPI with other proteins, such as silk fibroin to develop functional protein-based hybrid hydrogels with tunable structure and physicochemical properties. Silk fibroin (SF) is a widely recognized protein for biomedical applications, and we have recently reported the fabrication of pristine SF hydrogels, ${ }^{16}$ and SF-based hybrid ${ }^{17-18}$ and composite hydrogels ${ }^{19}$ via a fast and facile photocrosslinking method.

To optimize the physicochemical and biological properties of SPI-based hydrogels for desired biomedical applications, fundamental understanding of the colloidal structure of SPI dispersions, the hierarchical structure of the crosslinked hydrogels, and how the molecular building blocks transmit properties across the length scales in the macroscopic sample is pivotal. However, the hierarchical structure of SPI-based hydrogels is poorly understood, and there is a paucity of literature addressing this important issue. Small angle neutron scattering (SANS) is a powerful experimental technique for investigating the nanostructure and organization of proteins in concentrated solutions ${ }^{20}$ and hydrogels. ${ }^{21}$ Moreover, SANS is complementary to electron microscopy and is highly sensitive to hydrogen atoms in the system. ${ }^{19}$ Ultra-small angle neutron scattering (USANS) can provide structural information of hydrogels up to a length scale of several micrometers. ${ }^{22}$ Therefore, a combined SANS and USANS study offers the potential to develop in-depth understanding of the hierarchical structure of hydrogels over a wide length scale. In this paper, we investigate and report the development and structure-property relationship of photocrosslinked SPI and SPI/SF hybrid hydrogel systems for the first time through a combination of an array of complementary experimental techniques including scanning electron microscopy, X-ray diffraction, Raman 
and Fourier transform infrared spectroscopy, thermal analysis, SANS, USANS, rheology, water sorption and in vitro degradation studies.

\section{MATERIALS AND METHODS}

\section{Materials}

Soy protein isolate (Pro-Fam ${ }^{\circledR} 648$ with protein content over $90 \%$ ) was provided by Archer Daniels Midland (ADM), Australia. AAA grade Bombyx mori silk fiber top was purchased from Beautiful Silks, Australia. Tris(2,2-bipyridyl)dichlororuthenium(II) hexahydrate [RuII(bpy3)], ammonium persulfate (APS) and phosphate buffered saline (PBS) were purchased from Sigma-Aldrich, Australia. Deuterium oxide $\left(\mathrm{D}_{2} \mathrm{O}\right)$ was provided by the Australian Nuclear Science and Technology Organisation (ANSTO). All other chemicals used in this study were of analytical grade and purchased from Chem-Supply, Australia.

\section{Dispersion and solution preparation}

A $17.5 \mathrm{wt} \%$ SPI stock dispersion was prepared by mixing SPI powder with Milli-Q water. The mixture was stirred gently for 24 hours at $20^{\circ} \mathrm{C}$ to ensure complete hydration of the protein and homogeneity of the dispersion. A $17.5 \mathrm{wt} \%$ SF stock solution was prepared as described in our previous work. ${ }^{16}$ Briefly, raw Bombyx mori silk was degummed by boiling in aqueous sodium carbonate solution $(0.05 \mathrm{M})$ for $30 \mathrm{~min}$, washed with Milli-Q water thrice, and airdried at ambient temperature. The degummed fibroin was then dissolved in aqueous calcium chloride-water-ethanol solution (molar ratio 1:8:2) with a liquor ratio of 1:10 (solute:solvent) at $70{ }^{\circ} \mathrm{C}$ for 3 hours. The fibroin solution was then cooled, filtered through $5 \mu \mathrm{m}$ syringe filter, and dialyzed against Milli-Q water using 3.5K MWCO cellulose dialysis tube. The dialyzed fibroin solution was then centrifuged at 10,000 rpm for $30 \mathrm{~min}$, supernatant filtered through $0.8 \mu \mathrm{m}$ syringe filter, and concentrated by air-drying. The obtained SF stock solution was 
stored at $4{ }^{\circ} \mathrm{C}$ to prevent aging/gelation and used within 3 days. The amino acid composition of SPI and SF are given in Table S1 in Supporting Information.

\section{Hydrogel fabrication}

The list of hydrogel samples prepared, and their code names used in this paper are given in Table 1. For SPI gel pH7 sample fabrication, aqueous dispersion of SPI was mixed with RuII(bpy3), and APS to obtain a final mixture concentration of $15 \mathrm{wt} \%, 5 \mathrm{mM}$ and $28 \mathrm{mM}$, respectively. This mixture (ink) was then poured into a Teflon ${ }^{\circledR}$ mould and exposed to a $50 \mathrm{~W}$ LED white light for $2 \mathrm{~min}$. The gel formed was then turned over and exposed for a further 30 seconds to ensure complete crosslinking of the sample. For SPI gel pH12 sample fabrication, $10 \%$ potassium hydroxide solution was added dropwise to the SPI dispersion (to obtain a dispersion $\mathrm{pH}$ of 12) and stirred gently for $15 \mathrm{~min}$. RuII(bpy3) and APS was added to the above dispersion, mixed and photocrosslinked as described above. For SPI/SF hybrid hydrogel fabrication, SPI dispersion (at $\mathrm{pH} 7$ ) and SF solution were first mixed in different weight ratios $(1: 0,3: 1,1: 1,1: 3$ and $0: 1)$ for 3 hours to get a homogeneous mixture, and subsequently mixed with RuII(bpy3) and APS (ink) and photocrosslinked, as described above. The fabricated hydrogels were dialyzed against Milli-Q water to remove any excess material, and subsequently freeze-dried. The water uptake, hydrolytic degradation and viscoelastic properties of samples were measured after dialysis in equilibrium swollen condition, whereas other characterizations were performed using freeze-dried samples.

\section{Water uptake study}

The water uptake $(h)$ and cross-link density $\left(v_{e}\right)$ of fabricated hydrogels were calculated using equations 1 to $3 .^{16}$

$$
h=\frac{W_{s}-W_{d}}{W_{d}} \times 100
$$




$$
\begin{gathered}
v_{e}=\frac{-\ln \left(1-v_{1, s}\right)+v_{1, s}+X v_{1, s}}{V_{2}\left[v_{1, s}-\frac{1}{2} v_{1, s}\right]} \\
v_{1, s}=\frac{\frac{W_{d}}{\rho_{p}}}{\frac{W_{s} W_{d}}{\rho_{2}}+\frac{W_{d}}{\rho_{p}}}
\end{gathered}
$$

Where $W_{s}$ is the equilibrium swollen weight of hydrogel, $W_{d}$ is the dry weight of hydrogel, $v_{1, s}$ is the volume fraction of the hydrogel at the equilibrium swollen state, $\rho_{p}$ is the density of the dehydrated hydrogel (taken as $1.43 \mathrm{~g} / \mathrm{cm}^{3}$ for SPI and $1.42 \mathrm{~g} / \mathrm{cm}^{3}$ for SF), ${ }^{16,23} \rho_{2}$ is the density of water (taken as $0.997 \mathrm{~g} / \mathrm{cm}^{3}$ ), $X$ is the Flory-Huggins interaction parameter between that of the protein and water (taken as 0.50 for SPI and 0.95 for SF), ${ }^{16,23}$ and $V_{2}$ is the molar volume of water (taken as $18 \mathrm{~cm}^{3} / \mathrm{mol}$ ). ${ }^{16}$ The $W_{s}$ of hydrogel was measured after dialysis and removal of excess water using blotting paper, and $W_{d}$ of hydrogel was measured after air- and vacuumdrying. The experiments were repeated thrice, and the water uptake results are presented as mean values with standard deviation.

\section{In vitro degradation study}

To evaluate hydrolytic degradation of fabricated hydrogels in vitro, equilibrium swollen hydrogels were submerged in aqueous $10 \mathrm{mM}$ PBS solution ( $\mathrm{pH} 7.4)$ and equilibrated at $37^{\circ} \mathrm{C}$ for one month. The weight of the swollen hydrogel was measured initially $(w)$ and at periodic intervals $\left(w_{x}\right)$, respectively. The percentage of mass loss was calculated using the equation 4 . The experiments were repeated thrice, and the results are presented as mean values with standard deviation.

$$
\% \text { Mass Loss }=\frac{w-w_{x}}{w} \times 100
$$

\section{Scanning electron microscopy (SEM)}

The microstructure of freeze-dried hydrogel samples was examined using Philips XL30 Field Emission scanning electron microscope operated with an accelerating voltage of $10 \mathrm{kV}$. The 
freeze-dried hydrogels were cut to expose the cross-section and sputter-coated with platinum prior to the examination.

\section{X-ray diffraction (XRD)}

The secondary structure of the freeze-dried hydrogel samples was analyzed using Rigaku MiniFlex $600 \mathrm{X}$-Ray Diffractometer (using $\mathrm{Cu} \mathrm{k}_{\alpha}$ radiation, $\lambda=1.54$ ) operating at $40 \mathrm{kV}$ and 15 $\mathrm{mA}$. The scans were performed in continuous scanning mode from 5 to $60^{\circ}(2 \theta)$ with a step size of $0.02^{\circ}$ at a rate of $1.2 \% \mathrm{~min}$.

\section{Raman spectroscopy}

The secondary structure of freeze-dried SPI hydrogel samples was analyzed using Horiba Instruments LabRam 800HR Raman spectrometer equipped with an Olympus BX 30 fixedstage microscope. The samples were illuminated by a $633 \mathrm{~nm}$ He-Ne laser, generating an intensity of $10 \mathrm{~mW}$ at the sample, and the resulting spectra were recorded at ambient temperature using a Peltier-cooled CCD detector. The confocal hole and the entrance slit of the monochromator were fixed at 200 and $100 \mathrm{~mm}$, respectively. Measurements were performed in three replicates with 25 scans for each sample. The intensity and location of the phenylalanine band at $1003 \mathrm{~cm}^{-1}$ was used as an internal standard as it is non-sensitive to conformation or microenvironment. ${ }^{24}$

\section{Fourier transform infrared (FTIR) spectroscopy}

The secondary structure of freeze-dried SPI/SF hybrid hydrogel samples was analyzed using Thermo Fisher Nicolet 6700 FTIR spectrometer equipped with attenuated total reflection (ATR) accessory. The spectra were measured in the wavenumber range of $700-4000 \mathrm{~cm}^{-1}$.

\section{Thermal analysis}

The thermal transitions in freeze-dried hydrogel samples were investigated by thermogravimetric analysis (TGA) and differential scanning calorimetry (DSC). The thermal 
decomposition behavior of fabricated hydrogels was analyzed using Mettler Toledo TGA 1 thermal analyzer, operated under a controlled nitrogen gas flow rate of $25 \mathrm{~mL} / \mathrm{min}$. The temperature range of the measurement was 30 to $400{ }^{\circ} \mathrm{C}$ with a heating rate of $10{ }^{\circ} \mathrm{C} / \mathrm{min}$. The glass transition temperature $\left(T_{g}\right)$ of fabricated hydrogels was analyzed using TA Instrument Q2000 DSC thermal analyzer, operated under a controlled nitrogen gas flow rate of $40 \mathrm{~mL} / \mathrm{min}$. The samples were sealed in Tzero hermetic aluminum pans and an empty sealed pan was used as a reference. The temperature range of the measurement was 30 to $250{ }^{\circ} \mathrm{C}$ with a heating rate of $10^{\circ} \mathrm{C} / \mathrm{min}$.

\section{Rheology}

The rheological properties of aqueous SPI dispersions, fabricated hydrogels, and SPI/SF hybrid inks were analyzed using TA instrument HR-2 Discovery hybrid rheometer. To investigate the flow behavior of SPI dispersions and SPI/SF hybrid inks, dynamic viscosity measurement of the SPI dispersions (from 2 to $15 \mathrm{wt} \%$ ) and SPI/SF hybrid inks (15 $\mathrm{wt} \%$ protein concentration) were measured at ambient and dark environment, respectively across the shear rates from 0.01 $\mathrm{s}^{-1}$ to $2000 \mathrm{~s}^{-1}$ using $40 \mathrm{~mm}$ cone and plate geometry at a constant gap of $52 \mu \mathrm{m}$. After loading, the dispersion and ink samples were pre-sheared at $100 \mathrm{~s}^{-1}$ for 60 seconds and allowed to equilibrate for 600 seconds to ensure even distribution of the sample, and to exclude the loading effects. The viscosity recovery (structural recovery) measurements of SPI/SF hybrid inks were investigated using rotational rheology by varying shear rates with time. Briefly, the inks were loaded as described above and a shear rate of $0.1 \mathrm{~s}^{-1}$ was applied for 1 min followed by an increased shear rate of $50 \mathrm{~s}^{-1}$ for 10 seconds and a decreased shear rate of $0.1 \mathrm{~s}^{-1}$ for $1 \mathrm{~min}$. Dynamic oscillation rheology was employed to study the viscoelastic behavior of equilibrium water swollen hydrogels at 10\% compression using $20 \mathrm{~mm}$ parallel plate geometry. The strain sweep $(0.01$ to $5 \%)$ was performed at a constant frequency of $6.28 \mathrm{rad} / \mathrm{s}$, and the frequency sweep ( 0.1 to $50 \mathrm{rad} / \mathrm{s})$ was conducted at a constant strain of $0.1 \%$. The data were collected and 
processed using TRIOS software. The experiments were repeated thrice, and the results are presented as mean values with standard deviation.

\section{Small angle neutron scattering (SANS)}

The hierarchical structure of the SPI dispersion (prepared using $\mathrm{D}_{2} \mathrm{O}$ ) and equilibrium $\mathrm{D}_{2} \mathrm{O}$ swollen hydrogels were analyzed using the Bilby and Quokka SANS instruments, respectively at ANSTO. ${ }^{25-26}$ The neutron scattering length density (SLD) of $\mathrm{D}_{2} \mathrm{O}\left(6.36 \times 10-6 \AA^{-2}\right)$ provides good contrast against protein-based gels and also minimizes the incoherent scattering from hydrogen in the system. ${ }^{21}$ The dispersion samples were loaded into demountable Bilby cell assembly of $20 \mathrm{~mm}$ diameter and $1 \mathrm{~mm}$ path length. The $\mathrm{D}_{2} \mathrm{O}$ swollen hydrogels (approx. 1.5 $\mathrm{mm}$ thick) were cut into discs of $16 \mathrm{~mm}$ diameter and loaded into demountable Quokka cell assembly of $20 \mathrm{~mm}$ diameter and $2 \mathrm{~mm}$ path length, along with excess $\mathrm{D}_{2} \mathrm{O}$. The Bilby data were

collected in time-of-flight mode using wavelengths from 2 to $18 \AA$, in a singular detector setup with the back detector at $18 \mathrm{~m}$, and the curtain detectors at $4 \mathrm{~m}$ and $5 \mathrm{~m}^{25}$ The data were collected in the scattering vector, $q$ (equation 5) ${ }^{21}$ range of 0.001 to $0.3 \AA^{-1}$ :

$$
q=\frac{4 \pi \sin \theta}{\lambda}
$$

where $2 \theta$ is the angle of scattering, and $\lambda$ is the wavelength of neutrons. For the Quokka data, sample-detector distances of 2, 12 and $20 \mathrm{~m}$ with neutron wavelength of 5 and $8.1 \AA^{-1}$ (for lens optics), respectively were employed to cover the $q$ range of 0.0007 to $0.3 \AA^{-1} .^{26}$ All measurements were performed at $25{ }^{\circ} \mathrm{C}$ with a sample aperture diameter of $12 \mathrm{~mm}$. The obtained Bilby and Quokka data were reduced using the Mantid suit, and NCNR SANS reduction macros in the Igor software package, respectively. ${ }^{27}$ The data were transformed to absolute scale using an attenuated direct beam transmission measurement, and the $\mathrm{D}_{2} \mathrm{O}$ scattering was subtracted from the sample data using the PRIMUS computer program. ${ }^{28}$ 
Furthermore, the incoherent background scattering from respective data were determined with a high-q power law fit $\left(0.15 \AA^{-1}<\mathrm{q}<0.3 \AA^{-1}\right)$ using the SasView computer program (https://www.sasview.org/) and subtracted for analysis. ${ }^{21}$ Moreover, structural parameters of samples were determined by fitting desired model functions to SANS data using the SasView computer program.

\section{Ultra-small angle neutron scattering (USANS)}

USANS analysis was performed on equilibrium $\mathrm{D}_{2} \mathrm{O}$ swollen hydrogels using Kookaburra USANS instrument at ANSTO. ${ }^{29}$ The USANS instrument was operated with a neutron wavelength of $4.74 \AA$, and the identical SANS cells loaded with samples (used for SANS measurement) were used for USANS measurements. The scattering data were collected at ambient temperature in the $q$ range $0.00005-0.001 \AA^{-1}$ using a sample aperture of $12 \mathrm{~mm}$ diameter. The sample data were reduced with an empty SANS cell scattering using Python scripts running in Gumtree software based on the standard procedure. ${ }^{29}$ The data were then desmeared using the Lake algorithm (incorporated in the NIST USANS macros), and subsequently merged with the SANS data.

\section{RESULTS AND DISCUSSION}

\section{Aqueous dispersion of SPI}

Flow properties and critical crosslinking concentration of SPI dispersion. To determine the critical crosslinking concentration (concentration required for uniform network structure), rotational rheology was employed to investigate the flow behavior of aqueous SPI dispersion at $\mathrm{pH}$ 7. Figure $1 \mathrm{~A}$ shows the shear rate dependent apparent viscosity profile of SPI dispersion from 2 to $15 \mathrm{wt} \%$ concentration. It can be observed that the apparent viscosity of SPI dispersion showed a progressively increasing trend with increase in the concentration irrespective of the experimental shear rate. The increase in viscosity with increase in SPI concentration can be 
ascribed to the increase in the intermolecular non-covalent physical forces of attraction (hydrophobic and electrostatic interactions) between soy globulins due to increased molecular crowding. ${ }^{30}$ The primary structure of SPI is dominated by two major globulins, namely glycinin (11S) and $\beta$-conglycinin (7S) which have different secondary structures and properties. ${ }^{3}$ The quaternary structure of glycinin is complex and consists of six monomers (hexameric protein), where each subunit is made of an acidic chain (A) and a basic chain (B) linked by disulfide bonds. Based on homology, the five identified subunits of glycinin are divided into two groups. Group-1 members are methionine (Met) rich and have two cysteine (Cys) amino acid residues in basic chain and three Cys in the acidic chain segment. Group-2 members are relatively poor in Met. The quaternary structure of $\beta$-conglycinin is comprised of a hetero-trimer made of three subunits $\left(\alpha-68 \mathrm{kDa}, \alpha^{\prime}-72 \mathrm{kDa}\right.$, and $\left.\beta-52 \mathrm{kDa}\right)$ associated via hydrophobic interactions. ${ }^{31-32}$ The SPI dispersions showed shear thinning behavior (decrease in viscosity with increase in shear rate) for concentrations between 4 and $15 \mathrm{wt} \%$, indicating the presence of a network structure, which breaks down at higher shear rates, and is in general agreement with previous reports. ${ }^{4,30}$ The degree of shear thinning was observed to increase with increase in SPI concentration. Negligible shear thinning behavior was observed for $2 \mathrm{wt} \%$ sample, and the measured viscosity was nearly independent over a range of shear rate $\left(10-1000 \mathrm{~s}^{-1}\right)$. The viscosity of $15 \mathrm{wt} \%$ SPI dispersion at a low shear rate of $0.1 \mathrm{~s}^{-1}$ is more than four orders of magnitude higher when compared to viscosity at high shear rate $\left(2000 \mathrm{~s}^{-1}\right)$. This is because at very low shear rates the stable aggregates formed by the glycinin subunits of SPI are stabilized by disulfide bonds and the side chains are entangled with neighboring chains resulting in high viscosity. ${ }^{4}$ With the increase in shear rate, disentanglement of side chains and alignment of the molecules offer less shear resistance thereby decreasing the viscosity. ${ }^{4}$ For shear thinning fluids, the shear rate dependency of viscosity is described by power law model, as given in the equation $6 .{ }^{33}$

$$
\eta(\gamma)=\mathrm{K} \dot{\gamma}^{n-1}
$$


where $\eta(\gamma)$ is the viscosity, $K$ is the flow consistency index, $\gamma$ is the shear rate, and $n$ is the flow behavior index. The shear thinning curves (at concentrations between 4 and $15 \mathrm{wt} \%$ ) were fitted to equation 6 using power law regression (Figure S1 in Supporting Information), and the corresponding values of $K, n$ and coefficient of determination $\left(R^{2}\right)$ are given in Table S2 in Supporting Information. As the concentration of SPI is increased, the dispersion is found to be thicker ( $K$ increases) and more shear thinning ( $n$ decreases). ${ }^{34}$ At $15 \mathrm{wt} \%$ concentration, the dispersion becomes much thicker (good network structure) which resulted in drastic increase in viscosity, as shown in Figure 1B. Therefore, a concentration of $15 \mathrm{wt} \%$ was considered highly suitable for photocrosslinking SPI at steady state. Moreover, the measured viscosity of $15 \mathrm{wt} \%$ SPI dispersion is in the range of $0.83-4.27 \times 10^{4} \mathrm{~Pa} . \mathrm{s}$ at low shear rates of $0.1-0.01 \mathrm{~s}^{-1}$, a close range $\left(1.4-3.7 \times 10^{4} \mathrm{~Pa} . \mathrm{s}\right)$ reported for $3 \mathrm{D}$ printing polymer hydrogels. ${ }^{35}$
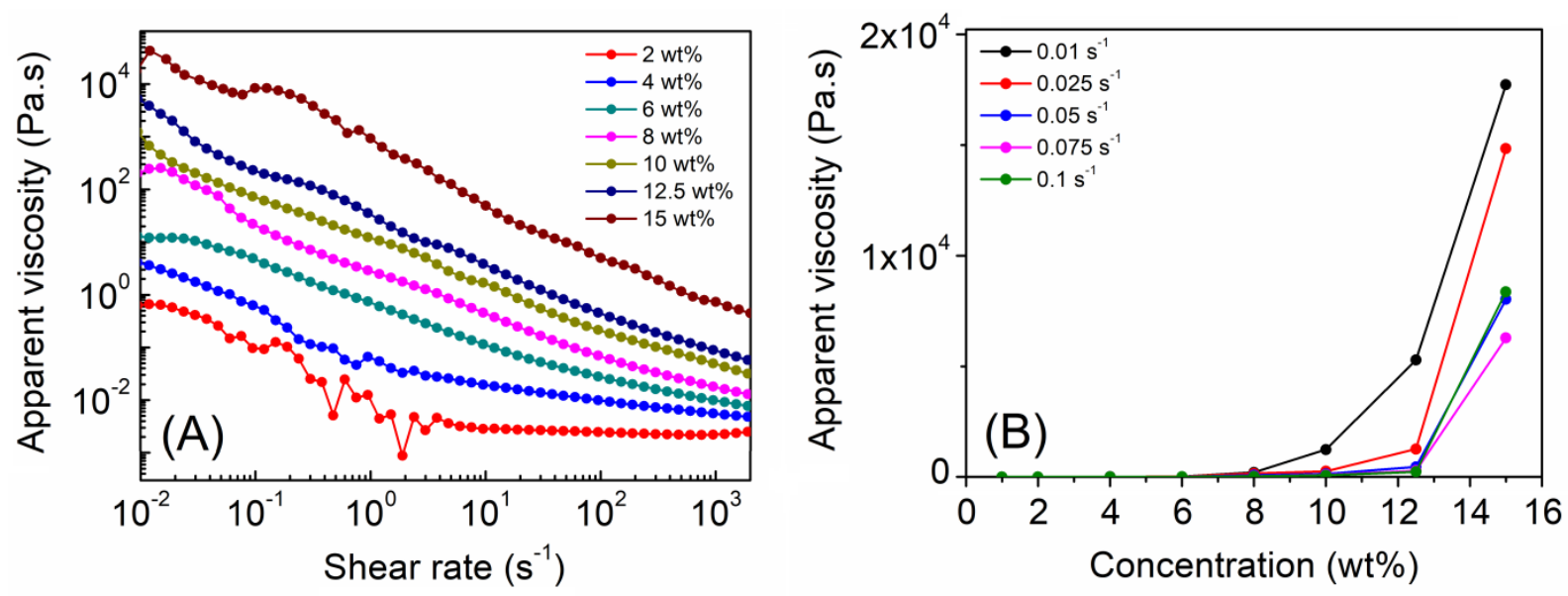

Figure 1. Rheological properties of SPI dispersion in water: (A) shear rate dependant viscosity profile (at different concentrations), and (B) concentration dependant viscosity profile (at different shear rate).

Effect of pH on the hierarchical structure of SPI dispersions: The hierarchical structure of aqueous SPI dispersion was studied at two different $\mathrm{pH}$ (7 and 12), as the molecular structure of SPI is often reported to be sensitive to $\mathrm{pH} .{ }^{3}$ Figure 2A compares the SANS intensity profile of $15 \mathrm{wt} \%$ SPI dispersed in $\mathrm{D}_{2} \mathrm{O}$ at $\mathrm{pH} 7$ and 12 . The plot shows three distinctive scattering 
regions: a high- $q$ region $\left(0.09<q<0.3 \AA^{-1}\right)$, a mid- $q$ region $\left(0.003<q<0.09 \AA^{-1}\right)$, and a low$q$ region $\left(0.001<q<0.003 \AA^{-1}\right)$. In general, the slope estimated from high- $q$ region (i.e. Porod region) of the small angle scattering data provides information about the "fractal dimension" of the formed structures (domains); whereas the low- $q$ and mid- $q$ region (i.e. Guinier region) allows for the estimation of fractal size. ${ }^{36}$ Thus the Porod region corresponds to a probed range smaller than the scattering objects and probing the local structure. The fractal dimension (Porod slope) of SPI was estimated as $\sim 2.9$ using a Power law fit at high- $q$ region $\left(0.1<\mathrm{q}<0.25 \AA^{-1}\right)$. Such a slope value represents 'mass fractal' in a branched system and gels; a colloidal dispersion with relatively dense internal structure. ${ }^{36}$ Such structure quality is typical to that of globular proteins in water and has been previously reported for other globular proteins such as bovine serum albumin. ${ }^{37}$ In SPI, this structural feature can be attributed predominantly to the $11 \mathrm{~S}$ glycinin. ${ }^{38}$ Moreover, a measured thermal glass transition $\left(T_{g}\right)$ of $\sim 215^{\circ} \mathrm{C}$ (Figure $\mathrm{S} 2$ in Supporting Information) supports the SPI to be $11 \mathrm{~S}$-enriched. ${ }^{39}$ The SANS data was further assessed by means of the Kratky plot (Figure 2B), which divides out the decay of the scattering at high- $q$ and shows certain other features more qualitatively evident. ${ }^{36}$ The Kratky plot of SPI at pH 7 clearly showed two broad peaks and a shoulder peak around $q$ value of $\sim 0.007 \AA^{-1}$, $\sim 0.02 \AA^{-1}$ and $\sim 0.09 \AA^{-1}$, respectively. Conversely, increasing $\mathrm{pH}$ of SPI dispersion from 7 to 12 showed decrease in intensity or disappearance of the peak at $q \sim 0.007 \AA^{-1}$, and the peak at $\sim 0.02 \AA^{-1}$ shifted towards higher- $q$ (i.e., smaller structures). Moreover, the zeta potential of SPI dispersion was measured to increase from $-15.24 \pm 0.40$ to $-32.15 \pm 1.20$ for changing $\mathrm{pH}$ from 7 to 12 . A change in the $\mathrm{pH}$ or ionic strength of the dispersion media has been previously reported to degrade or dissociate $11 \mathrm{~S}$ structure of glycinin due to increased electrostatic repulsion. ${ }^{40-41}$ The observed difference in scattering with change in $\mathrm{pH}$ is related to the unfolding/dissociation and/or re-association of $11 \mathrm{~S}$ and their aggregates resulting in increased solubility at $\mathrm{pH} 12$ (observed with change in dispersion colour from turbid to clear, as seen in 
Figure $3 \mathrm{~A}){ }^{3,}{ }^{42}$ To gain further insights into the conformational changes and organization of SPI at different $\mathrm{pH}$ in detail, the SANS data were fitted (Figure $2 \mathrm{C}$ and 2D) with shapeindependent form factor models (Guinier-Porod + power law) to estimate structural parameters. The Guinier-Porod model calculates the scattering for a generalized Guinier/power law object that can be used to determine the size and dimensionality of scattering objects. ${ }^{43}$ A dimension variable, $\mathrm{S}=0$ (for $3 \mathrm{D}$ globular structures) was used for Guinier-Porod fitting. ${ }^{43}$ The fits returned a radius of gyration $\left(R_{g}\right)$ of $\sim 26.9 \mathrm{~nm}, \sim 8.0 \mathrm{~nm}$ and $\sim 2.0 \mathrm{~nm}$ for the peaks, which may be attributed to the glycinin subunits such as $>15 \mathrm{~S}$ (unresolved $11 \mathrm{~S}$ aggregates), $11 \mathrm{~S}$ and $3 \mathrm{~S}$, respectively. ${ }^{44-45}$ The $3 \mathrm{~S}$ structure is the $11 \mathrm{~S}$ dissociated structure containing one acidic and one basic polypeptides (building block of $11 \mathrm{~S}$ ). ${ }^{40,45}$ The $R_{g}$ of two peaks for $\mathrm{pH} 12$ sample was determined to be $\sim 5.9 \mathrm{~nm}$ and $\sim 2.0 \mathrm{~nm}$, which may be attributed to $\overline{7 \mathrm{~S}}$ (glycinin trimer, different to $\beta$-conglycinin) and 3S glycinin subunits, respectively. ${ }^{44-45}$ This observation suggests that, at $\mathrm{pH} 12$, the $11 \mathrm{~S}$ glycinin of SPI dissociates and/or re-associates into $7 \mathrm{~S}$ glycinin trimers, and the SANS Porod slope at high- $q$ corresponds to the intrinsic structure of 3 S glycinin subunits. ${ }^{40}$, ${ }^{45}$ Moreover, the absence of Guinier plateau and the observed increase in intensity at the low$q$ region signifies intermolecular interactions (large agglomeration trending beyond SANS measurement range) or network structure in the system, ${ }^{46}$ which is in general agreement with rheology results. 

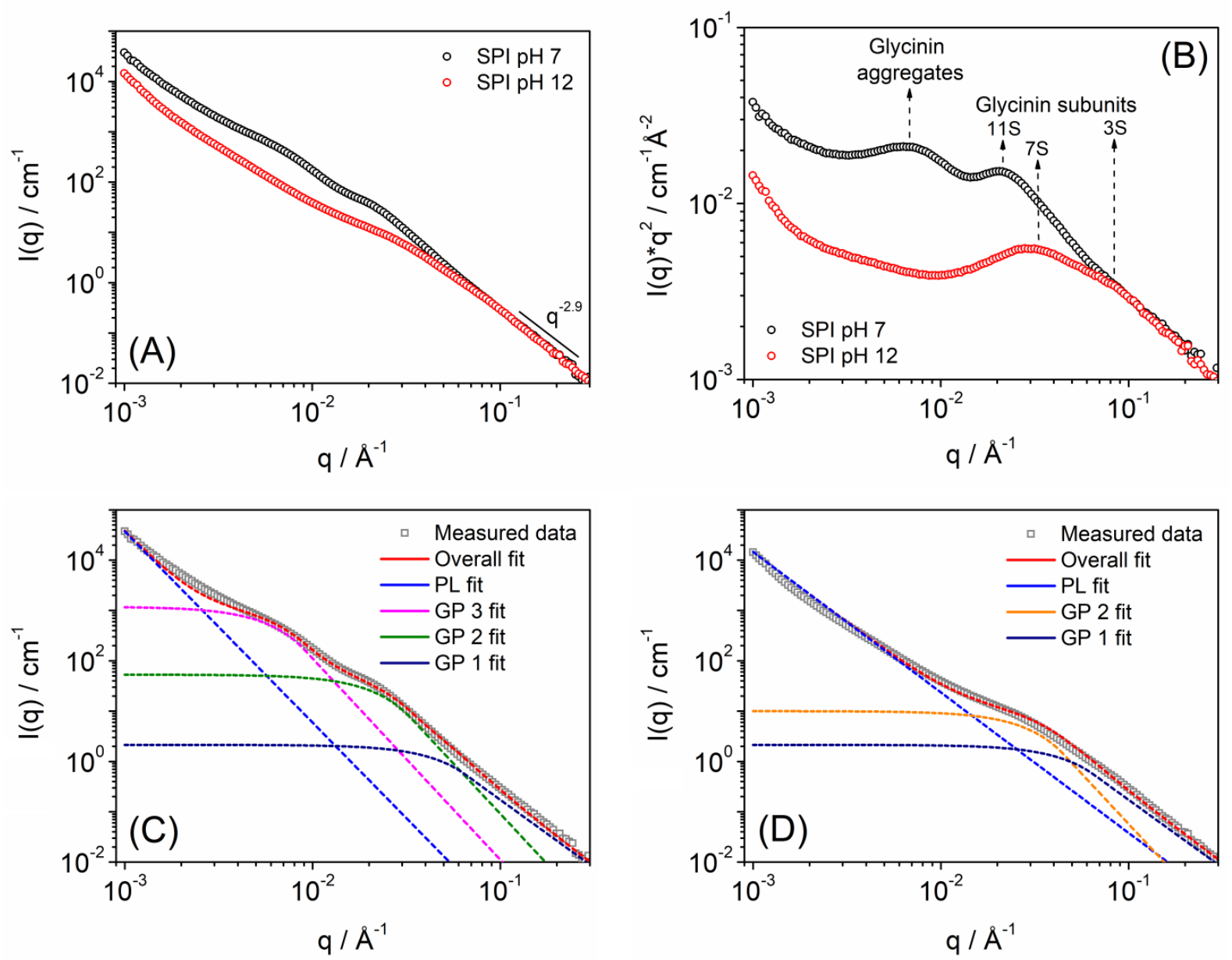

Figure 2. (A) SANS intensity profile, and (B) Kratky plot of $15 \mathrm{wt} \%$ SPI dispersion in $\mathrm{D}_{2} \mathrm{O}$. (C) and (D) are shape-independent form factor models (Guinier-Porod (GP) + power law (PL)) fit to SANS data of SPI at $\mathrm{pH} 7$ and 12 , respectively.

\section{Photocrosslinked SPI hydrogels:}

Effect of pH on the water uptake and microstructure of SPI hydrogels. The SPI used in this study has a $38.6 \mathrm{~mol} \%$ non-polar, $47.6 \mathrm{~mol} \%$ charged polar, and $13.8 \mathrm{~mol} \%$ uncharged polar amino acids with a tyrosine content of $3.7 \mathrm{~mol} \%$ (Table S1 in Supporting information), which can be potentially used for fabrication of photocrosslinked hydrogel via dityrosine crosslinking. ${ }^{16}$ Moreover, the ruthenium-persulfate cross-linking system used to fabricate hydrogels in this work has been previously reported (at similar concentration range) to be nontoxic and minimally inflammatory (after 30 days) to mammalian cells, which supports the 
applied cross-linking method to be completely biological. ${ }^{47}$ Figure $3 \mathrm{~A}$ shows the schematic of photocrosslinked SPI hydrogel fabrication (see Figure S3 in Supporting Information for full reaction mechanism), and the optical images of equilibrium water swollen hydrogels. With SPI exhibiting different structural conformations at pH 7 (closed) and $\mathrm{pH} 12$ (open) studied by SANS, SPI hydrogels were photocrosslinked at $\mathrm{pH} 7$ and 12 to study their structure-property differences. The photocrosslinked SPI hydrogels swelled macroscopically when exposed to water and became brittle when dry. Water swelling is an important property of hydrogels to be considered for tissue engineering applications, which directly relates to the diffusive and transport properties of nutrients/gases/regulatory factors, and facilitate cell-biomaterial interactions, cell differentiation and proliferation. ${ }^{48}$ Moreover, the balance between water uptake $(h)$ and mechanical strength is of critical importance for application of hydrogels in the field of tissue engineering, where the strength of the hydrogel is dictated by its crosslink density $\left(v_{e}\right)$, which can be calculated from water uptake results using the equation $2 .{ }^{19}$ The $h$ and $v_{e}$ values of fabricated SPI hydrogels measured from water uptake study are presented in Table 1. The SPI hydrogel photocrosslinked at $\mathrm{pH} 7$ (SPI gel pH7) exhibited a $h$ and $v_{e}$ value of $\sim$ $662 \%$ and $0.283 \times 10^{-3} \mathrm{~mol} / \mathrm{cm}^{3}$, respectively; where the $h$ value of fabricated hydrogel is five time higher than extruded soy protein sheets, ${ }^{49}$ and ten times higher than amino crosslinked soy protein hydrogels. ${ }^{10}$ The SPI gel $\mathrm{pH} 7$ exhibited a particulate microstructure (Figure 3B), which is due to the globular (closed) structural configuration of SPI (as seen from SANS results) during crosslinking, and is similar to microstructure of hydrogels crosslinked using glyceraldehyde and/or glutaraldehyde. ${ }^{10}$ Conversely, the SPI hydrogel photocrosslinked at $\mathrm{pH}$ 12 (SPI gel pH12) exhibited a $h$ and $v_{e}$ value of $\sim 1946 \%$ and $0.279 \times 10^{-3} \mathrm{~mol} / \mathrm{cm}^{3}$, respectively; where the $h$ value of fabricated hydrogel is two times higher than soy protein/poly $(\mathrm{N}-$ isopropylacrylamide) interpenetrating polymer network hydrogels. ${ }^{50}$ The significantly higher $h$ value measured for SPI gel $\mathrm{pH} 12$ is attributed to the increased hydrophilicity and solubility 
he unfolded state of SPI globulins (as seen from SANS results) at photocrosslinking $\mathrm{pH}$ of 12 create large $(4-6 \mu \mathrm{m})$ ordered porous microstructure and channels that can be clearly observed in SEM micrographs (Figure 3B). The porosity of a hydrogel is related to its unbound water accomadation, which directly influences the water uptake. The lower $h$ and higher $v_{e}$ value of SPI gel $\mathrm{pH} 7$ could greatly influence its mechanical properties.

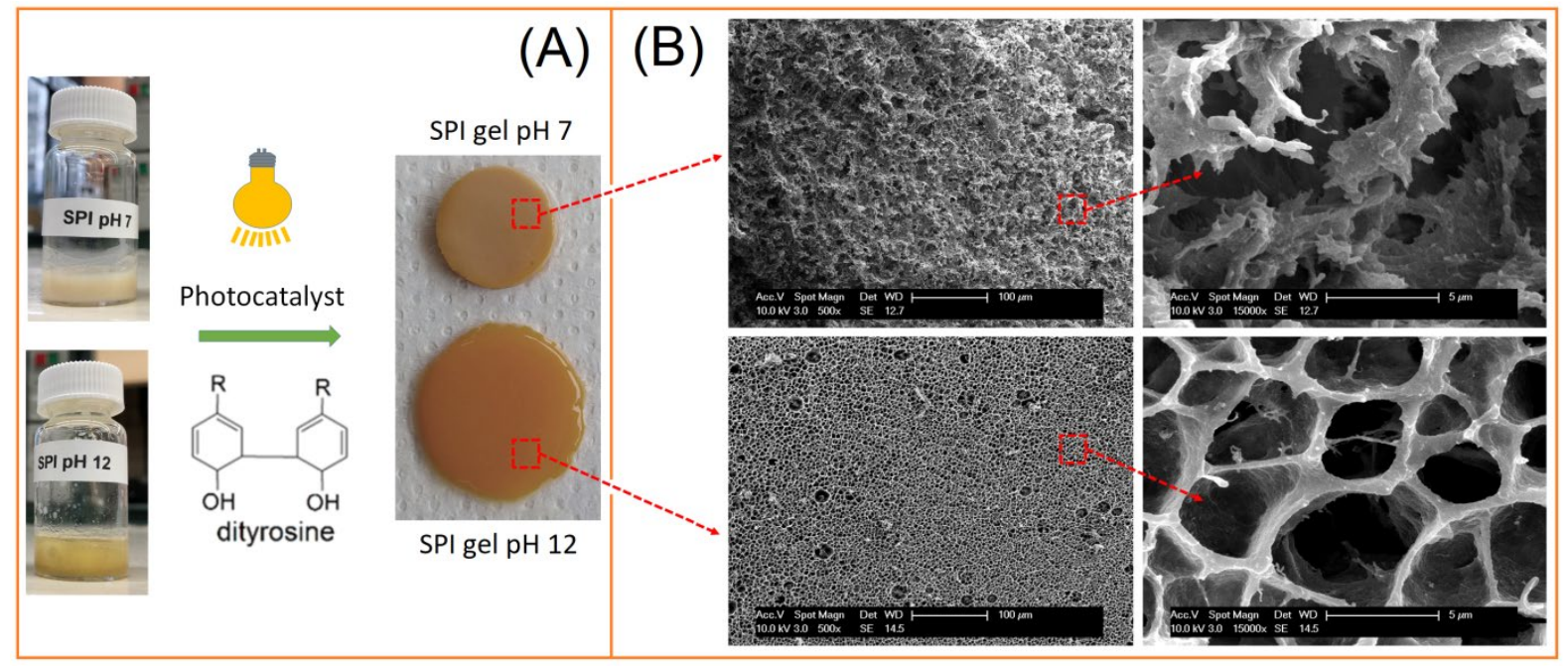

Figure 3. (A) Schematic of photocrosslinked SPI hydrogel fabrication with optical pictures of dispersion and equlibrium water swollen hydrogels. (B) SEM micrographs of respective freezedried hydrogels.

Table 1: Water uptake and thermal analysis results of photocrosslinked hydrogels.

\begin{tabular}{lcccc}
\hline Sample* & $\begin{array}{c}\text { Mass ratio } \\
\text { (SPI:SF) }\end{array}$ & $\begin{array}{c}\text { Water } \\
\text { uptake, } \boldsymbol{h}(\mathbf{\%})\end{array}$ & $\begin{array}{c}\text { Crosslink density, } \\
\boldsymbol{v}_{\boldsymbol{e}}\left(\times \mathbf{1 0}^{-\mathbf{3}} \mathbf{\mathbf { m o l }} \mathbf{c m}^{-\mathbf{3}}\right)\end{array}$ & $\begin{array}{c}\text { Glass transition } \\
\text { temperature, } \boldsymbol{T}_{\boldsymbol{g}} \\
\left({ }^{\mathbf{C}} \mathbf{C}\right)\end{array}$ \\
\hline SPI gel pH12 & $1: 0$ & $1946 \pm 98$ & 0.279 & - \\
SPI gel pH7 & $1: 0$ & $662 \pm 33$ & 0.283 & 207.57 \\
SPI/SF (3:1) & $3: 1$ & $1497 \pm 74$ & 0.293 & 181.16 \\
gel & & & & 179.73 \\
SPI/SF (1:1) & $1: 1$ & $1895 \pm 94$ & 0.304 & \\
gel & & &
\end{tabular}


SPI/SF (1:3)

\section{$1: 3$}

$2864 \pm 143$

0.317

gel

SF gel

$0: 1$

$2362 \pm 118$

0.330

168.85

*The SPI gel pH12 sample was photocrosslinked at pH 12, whereas all other samples at pH 7.

Effect of pH on the secondary structure of SPI hydrogels. To determine the secondary structural differences of photocrosslinked SPI hydrogels, SPI powder and hydrogels were qualitatively and quantitatively characterized using XRD and Raman spectroscopy. The XRD pattern of SPI powder and hydrogels (Figure 4A) exhibited semi crystalline nature with major $2 \theta$ peaks observed at $9.8^{\circ}$ and $19.8^{\circ}$ which corresponds to $\alpha$-helix and $\beta$-sheet structures, respectively. ${ }^{51-52} \mathrm{Several}$ broad/shoulder peaks around $2 \theta$ value of $16^{\circ}, 25^{\circ}$ and $42^{\circ}$ were also observed. However, there remains paucity of information on designation of these peaks to SPI. On the other hand, secondary structures of other semi crystalline protein such as SF have been extensively studied using XRD, and several other peaks corresponding to $\alpha$-helix, $\beta$-sheets, $\beta$ strands, turns and unordered structures have been reported. ${ }^{19,53}$ We attempted to estimate the quantitative secondary structural information of SPI powder and hydrogels by deconvoluting the XRD data (Figure S4 in Supporting Information) with $2 \theta$ peaks reported for $\alpha$-helix $\left(9.3^{\circ}\right.$, $12.3^{\circ}$ and $\left.15.8^{\circ}\right), \beta$-sheets/strands $\left(19.8^{\circ}, 22.8^{\circ}\right.$ and $\left.24.7^{\circ}\right)$ and turns/unordered $\left(28.2^{\circ}, 32.4^{\circ}\right.$, $40.0^{\circ}$ and $49.4^{\circ}$ ) structures of SF. ${ }^{19,53}$ The data were deconvoluted using the MagicPlot software (https://magicplot.com/) with Gaussian curve fitting, and the estimated secondary structural content of SPI is presented in Figure 4B. The estimated secondary structures for SPI powder ( $\alpha$-helix $\sim 22 \%, \beta$-sheets/strands $\sim 44 \%$, and turns/unordered $\sim 34 \%$ ) is in general agreement with values reported previously. ${ }^{24}$ It can be observed that the SPI powder and SPI gel pH7 exhibited similar secondary structure contents, whereas, SPI gel pH12 showed decrease in the $\beta$-content and subsequent increase in turns/unordered structure. Figure $4 \mathrm{C}$ shows the Raman spectra of SPI powder and hydrogels with characteristic frequency peaks 
observed for amide I (1620-1720 $\left.\mathrm{cm}^{-1}\right)$, aromatic amino acids $\left(1590-1620 \mathrm{~cm}^{-1}\right.$ and $1160-1250$ $\left.\mathrm{cm}^{-1}\right)$, amide II (1520-1590 $\left.\mathrm{cm}^{-1}\right), \mathrm{C} \alpha-\mathrm{H}$ deformation $\left(1450 \mathrm{~cm}^{-1}\right)$, amide III (1250-1360 $\left.\mathrm{cm}^{-1}\right)$, phenylalanine doublet $\left(970-1055 \mathrm{~cm}^{-1}\right), \mathrm{C} \alpha-\mathrm{C}$ stretch $\left(935 \mathrm{~cm}^{-1}\right)$, tyrosine doublet $(830-850$ $\left.\mathrm{cm}^{-1}\right)$ and tryptophan $\left(756 \mathrm{~cm}^{-1}\right) \cdot{ }^{54-55}$ The amide I band of Raman spectra is related to changes in protein backbone conformation (involving mainly $\mathrm{C}=\mathrm{O}$ stretching vibrations, and partly $\mathrm{N}-$ $\mathrm{H}$ in-plane bending of peptide groups) and is widely employed in determining secondary structure of proteins. ${ }^{24}$ The amide I band of Raman spectra were deconvoluted (Figure S5 in Supporting Information) with frequencies corresponding to $\alpha$-helix $\left(1656 \mathrm{~cm}^{-1}\right)$, $\beta$ sheets/strands $\left(1633 \mathrm{~cm}^{-1}\right.$ and $\left.1669 \mathrm{~cm}^{-1}\right)$, turns/random coil $\left(1643 \mathrm{~cm}^{-1}, 1685 \mathrm{~cm}^{-1}, 1698 \mathrm{~cm}^{-1}\right.$ and $1715 \mathrm{~cm}^{-1}$ ) structures, ${ }^{54-55}$ and the estimated secondary structural content of SPI is presented in Figure 4D. The secondary structural information obtained by Raman analysis is in good agreement with XRD results. The polymorph $\alpha$-form (type II $\beta$-turn and may be less extended helix) is hydrophilic in nature, whereas $\beta$-form (antiparallel $\beta$-pleated sheets and aggregated strands) is hydrophobic. ${ }^{19}$ Therefore, the higher $h$ value exhibited by SPI gel pH12 is due to its relatively higher content of $\alpha$-form and unordered structures (due to dissociated state of glycinin 11S during crosslinking, as seen from SANS results), which could greatly influence its hydrophilicity and degradation behavior. This is to note that $h$ value is also dependent on the nature of the pores and pore volume. 

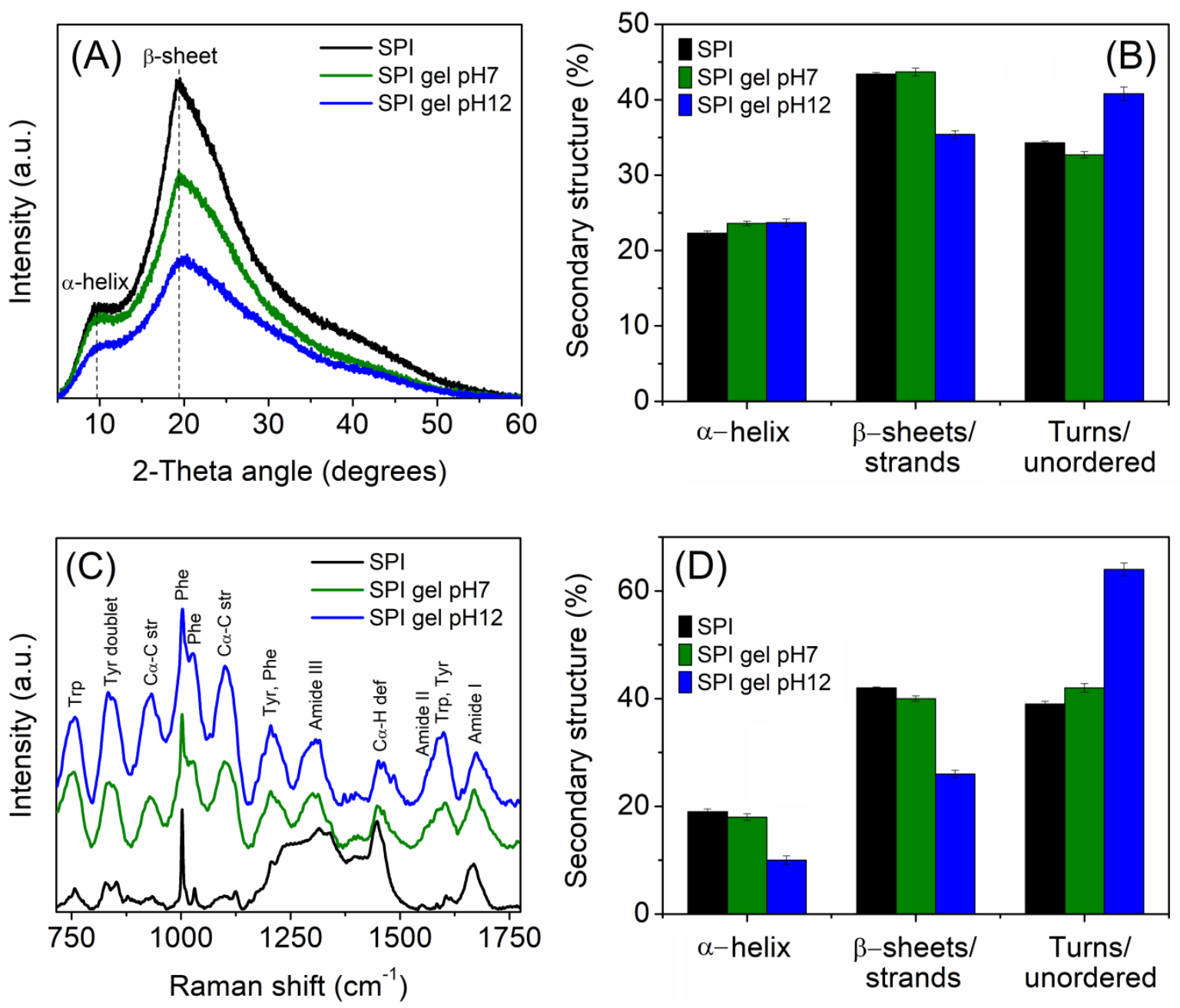

Figure 4. (A) X-ray diffractogram, (B) quantitative secondary structure estimates from XRD data, (C) Raman spectra, and (D) quantitative secondary structure estimates from Raman spectroscopy data of photocrosslinked SPI hydrogels compared with SPI powder.

Effect of pH on the viscoelastic properties of SPI hydrogels. Protein-based hydrogels exhibit complex viscoelastic properties, which strongly correlate with their hierarchical structure, $h, v_{\mathrm{e}}$ and degree of crystallinity. The viscoelastic properties of photocrosslinked SPI hydrogels were measured using dynamic oscillatory rheology in both strain and frequency sweep modes to compare its suitability for human lumbar nucleus pulposus tissue engineering, reported at similar experimental conditions. ${ }^{15}$ The strain sweep was performed to determine the linear viscoelastic region of SPI hydrogels with respect to strain, whereas frequency sweep to 
determine the linear equilibrium modulus plateau. ${ }^{56}$ Figure 5 shows the measured storage modulus (G') and loss modulus (G') of equilibrium water swollen SPI hydrogels in the linear viscoelastic regime; where $G^{\prime}$ is observed to be greater than $G^{\prime}$ ' in the whole measurement range, and therefore the elastic response of SPI hydrogels is greater than viscous nature. In both modes, the G' and G', of SPI gel pH7 was observed to be an order of magnitude higher than SPI gel pH12. Moreover, G' was observed to be nearly independent of strain over a range of 0.01-0.1 strain $\%$. However, with increase in strain beyond $1 \%$, the $\mathrm{G}$ ' begins to drop indicating network fracture. ${ }^{56-57}$ Therefore, a strain of $0.1 \%$ was used to evaluate the frequency dependency of the hydrogels. At low frequencies the samples showed nearly frequency independent behavior. However, at a higher frequency (i.e. low relaxation time), the marginal increase in modulus indicates diminishing of the sample flexibility and increase in mechanical rigidity. At $0.1 \%$ strain, the SPI gel $\mathrm{pH} 7$ exhibited a $\mathrm{G}^{\prime}$ value of $\sim 7.7 \mathrm{kPa}$, whereas SPI gel pH12 exhibited $\sim 0.8 \mathrm{kPa}$, respectively. The obtained modulus values of SPI gel $\mathrm{pH} 7$ are significantly higher than that reported for thermal-set, ${ }^{4}$ enzyme ${ }^{8}$ and glutaraldehyde ${ }^{10}$ crosslinked soy protein hydrogels, and is in the range of human lumbar nucleus pulposus. ${ }^{15}$ The higher $\mathrm{G}^{\prime}$ magnitude and tan delta $(\sim 0.17)$ observed for SPI gel $\mathrm{pH} 7$ directly implies that it is much stiffer than SPI gel pH12 (tan delta $\sim 0.13$ ), ${ }^{58}$ which can be attributed to its structural organization, higher $v_{\mathrm{e}}$ and lower $h$ values. The SPI gel $\mathrm{pH} 12$ is extremely soft that may deform under its own weight, and make manual handling of the sample a rather difficult experimental task, which may be the reason for observed fluctuations in dynamic frequency and strain sweeps measurements. 

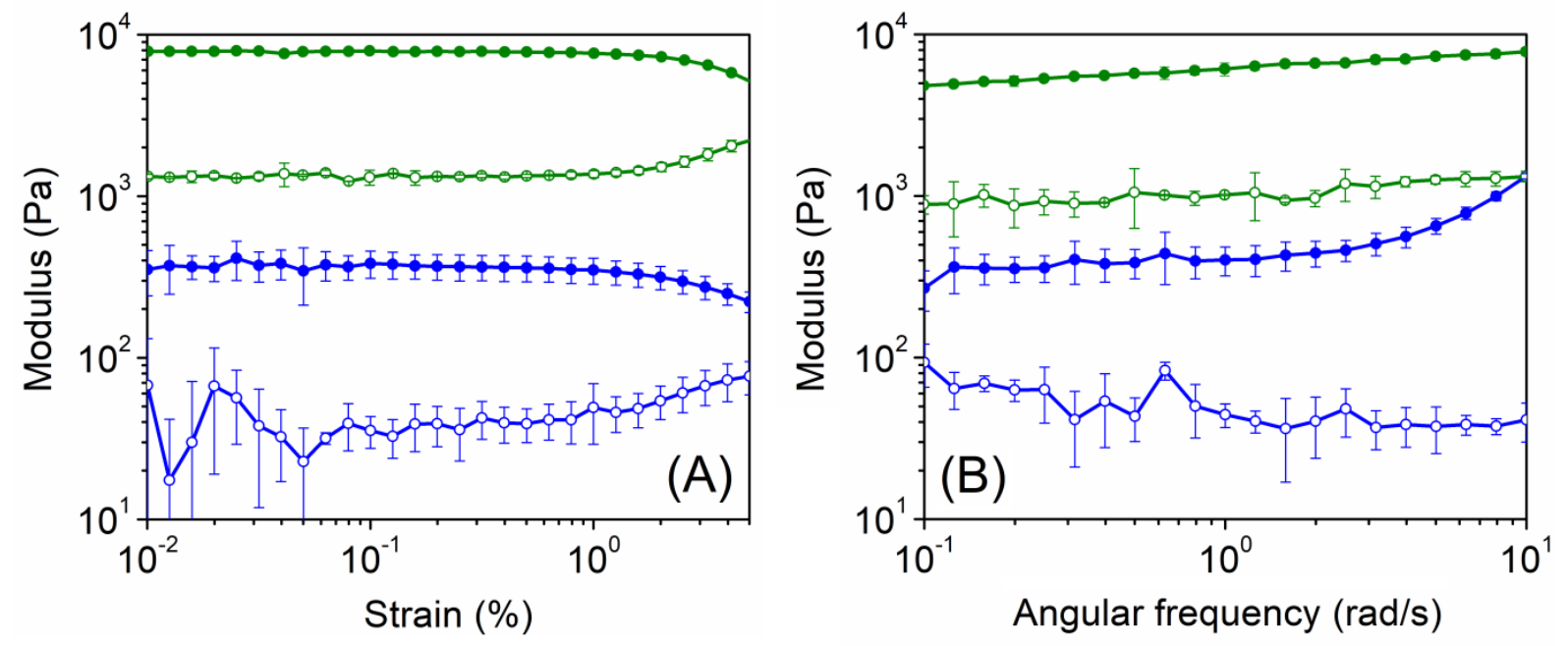

$$
\begin{array}{ll}
\multimap-G^{\prime}(\mathrm{SPI} \text { gel pH7) } & \multimap \mathrm{G}^{\prime}(\mathrm{SPI} \text { gel pH12) } \\
\multimap-\mathrm{G}^{\prime}(\mathrm{SPI} \text { gel } \mathrm{pH} 7) & \multimap \mathrm{G}^{\prime}(\mathrm{SPI} \text { gel pH12) }
\end{array}
$$

Figure 5. Dynamic viscoelastic properties of photocrosslinked SPI hydrogels. (A) and (B) are strain and frequency sweep, respectively.

Effect of pH on the hydrolytic degradation of SPI hydrogels. The in vivo application of protein-based hydrogels for tissue engineering requires that the hydrogel degrades in a controlled rate under physiological conditions. Therefore, the photocrosslinked SPI hydrogels were investigated for in vitro hydrolytic degradation in $10 \mathrm{mM}$ PBS (pH 7.4), which match the osmolarity and ion concentrations of the human body. Figure 6 shows the in vitro degradation behavior of photocrosslinked SPI hydrogels in PBS over a period of 18 days. It was observed that the SPI gel pH12 degraded faster, showing around 52\% mass loss in 7 days after which it lost its structural integrity; whereas, the SPI gel $\mathrm{pH} 7$ showed structural integrity up to 18 days retaining $\sim 62 \%$ of mass, which is higher than soy hydrogels reported by thermal treatment, ${ }^{59}$ and enzyme crosslinking. ${ }^{60}$ The observed higher water-resistance or stability of SPI gel pH7 could be attributed to its higher globular nature. 


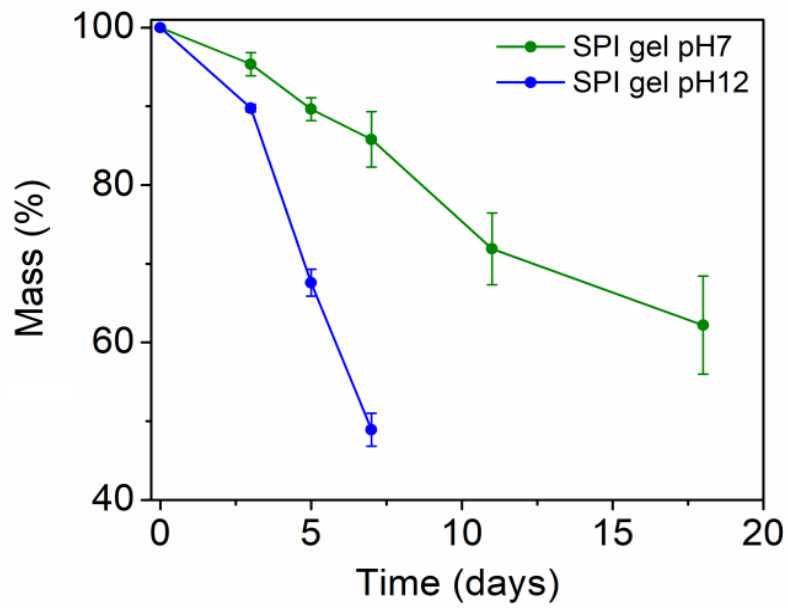

Figure 6. In vitro degradation behavior of photocrosslinked SPI hydrogels in phosphate buffered saline ( $\mathrm{pH} 7.4)$.

\section{Photocrosslinked SPI/SF hybrid hydrogels}

Water uptake and microstructure of hybrid hydrogels. The SPI photocrosslinked at pH 7 exhibited particulate microstructure, and higher mechanical and water-resistant properties compared to SPI photocrosslinked at $\mathrm{pH}$ 12. Therefore, $\mathrm{pH} 7$ was selected to blend and cocrosslink SPI and SF to study the effect of SF content on the structure and properties of photocrosslinked SPI/SF hybrid hydrogels. The equilibrium swelling and microstructure of SPI/SF hybrid hydrogels was evaluated using water uptake and SEM (Figure 7) study. The $h$ and $v_{\mathrm{e}}$ values of SPI/SF hybrid hydrogels obtained from water uptake results are provided in Table 1. The pristine SF gel exhibited relatively higher $h$ and $v_{\mathrm{e}}$ values compared to SPI gel pH7. The obtained $v_{\mathrm{e}}$ value for SF gel $\left(0.330 \times 10^{-3} \mathrm{~mol} / \mathrm{cm}^{3}\right)$ is in general agreement with previous reports. ${ }^{16,19}$ The relatively higher $h$ value of SF gel can be attributed to its highly ordered porous microstructure, whereas the higher $v_{\mathrm{e}}$ value can be attributed to its higher tyrosine content (5.6 mol\%; Table S1 in Supporting Information). The particulate structure of SPI gel pH7 is due to the globular (closed) structural configuration of SPI (largely 11S glycinin and aggregates, as seen from SANS results) during crosslinking, whereas the ordered porous 
microstructure of SF gel is attributed to the random coil configuration of silk molecules during crosslinking. ${ }^{21}$ It can be observed that the macroscopic size of the equilibrium water swollen SPI/SF hybrid hydrogels (Figure 7), and their porous microstructure and order increases with increase in SF content. The SPI/SF (1:1) and SPI/SF (1:3) hybrid hydrogels exhibited ordered, interconnected and interpenetrated 3D porous microstructure network. The order and average pore size of SPI/SF (3:1) hybrid hydrogel is random and small in nature. The $h$ and $v_{\mathrm{e}}$ values along with porosity of SPI/SF hybrid hydrogels also increased with increase in SF content. Interestingly, the SPI/SF (1:3) gel exhibited the highest $h$ value amongst the fabricated hydrogels, whereas the SF gel exhibited the highest $v_{\mathrm{e}}$. In co-crosslinked SPI/SF hybrid hydrogels, the di-tyrosine crosslinks can occur between SPI-SPI, SPI-SF, and SF-SF chains. It is also reported that the order or arrangement of secondary structure also influences the $h$ value of SF gel. ${ }^{21}$ Therefore, given the complexity of the system, the difference in $v_{\mathrm{e}}$ of fabricated hydrogels may be attributed to tyrosine content in the sample; whereas, the difference in $h$ value of hydrogels may be due to the difference in hierarchical structure, secondary structures and molecular chain mobility. ${ }^{21}$ The obtained $h$ values of photocrosslinked SPI/SF hybrid hydrogels are comparable to those of photocrosslinked SF/polyvinyl alcohol hydrogels. ${ }^{61}$ The difference in $h$ and $v_{\mathrm{e}}$ values of SPI/SF hybrid hydrogels are expected to greatly influence their mechanical and degradation properties. 

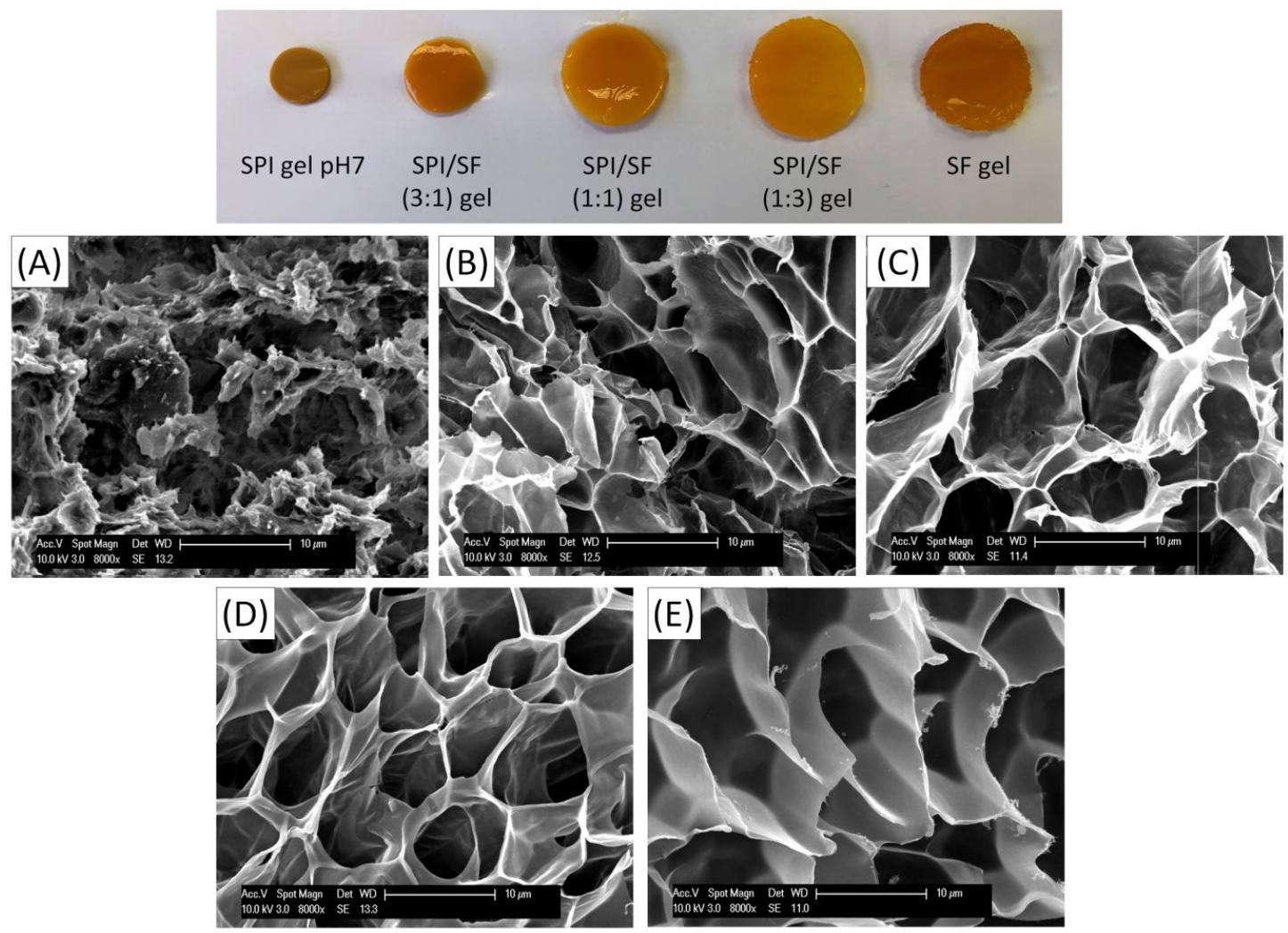

Figure 7. Optical pictures and SEM micrographs of freeze-dried SPI/SF hybrid hydrogels compared to pristine SPI and SF hydrogels: (A) SPI gel pH7, (B) SPI/SF (3:1), (C) SPI/SF (1:1), (D) SPI/SF (1:3), and (E) SF gel.

Secondary structure and molecular chain mobility of hybrid hydrogels. The effect of SF content on the secondary structure of SPI/SF hybrid hydrogels was characterized both qualitatively and quantitatively using XRD and FTIR spectroscopy. The XRD pattern of SPI/SF hybrid hydrogels is compared to pristine SPI and SF hydrogels in Figure 8A. The SPI gel $\mathrm{pH} 7$ exhibited semi crystalline nature with two major $2 \theta$ peaks observed at $9.8^{\circ}$ and $19.8^{\circ}$ respectively, which corresponds to $\alpha$-helix and $\beta$-sheet structures (as discussed earlier). Conversely, the SF gel exhibited semi crystalline nature with one major broad peak around $21.9^{\circ}$, indicating the presence of both polymorphs of silk: silk I ( $\alpha$-form-type II $\beta$-turn and may be less extended helix) and silk II ( $\beta$-form-antiparallel $\beta$-pleated sheets) structures. ${ }^{16,53}$ For SPI/SF hybrid hydrogels, the intensity of $\alpha$-helix peak were observed to gradually decrease 
with increase in SF content. The observed decrease in intensity of $\alpha$-helix peak with the increase in SF content may be due to the increased glycine amino acid content (from SF) in the system, which may act as a $\alpha$-helix breaker for SPI structures. ${ }^{62}$ In order to delve deeper understanding of the secondary structure of SPI/SF hybrid hydrogels and their associated properties, the XRD spectrum of fabricated hydrogels were deconvoluted (Figure S6 in supporting information) with $2 \theta$ peaks corresponding to $\alpha$-helix $\left(9.3^{\circ}, 12.3^{\circ}\right.$ and $\left.15.8^{\circ}\right), \beta$ sheets/strands $\left(19.8^{\circ}, 22.8^{\circ}\right.$ and $\left.24.7^{\circ}\right)$ and turns/unordered $\left(28.2^{\circ}, 32.4^{\circ}, 40.0^{\circ}\right.$ and $\left.49.4^{\circ}\right)$ structures. ${ }^{19,53}$ The estimated secondary structural contents are presented in Figure 8B. It can be observed that the secondary structure of SPI gel pH7 and SF gel samples are dominated by $\beta$-sheet/strand structures. However, with increase in SF content, SPI/SF hybrid hydrogels exhibited a decrease trend in $\alpha$-helix and $\beta$-sheet/strand structures, and subsequently increase in turns/unordered structure. The increase in unordered structure of SPI/SF hybrid hydrogels with increase in SF content is in general agreement with water uptake results. Figure $8 \mathrm{C}$ compares the FTIR spectra of SPI/SF hybrid hydrogels to pristine SPI and SF hydrogels. The spectra exhibited two major peaks between $1600-1700 \mathrm{~cm}^{-1}$ and $1500-1600 \mathrm{~cm}^{-1}$, corresponding to amide I and amide II conformational bands of proteins. The secondary structural estimates of fabricated hydrogels were obtained by deconvoluting (Figure S7 in Supporting Information) the FTIR amide I band with frequencies corresponding to $\alpha$-helix (1656-1662 $\left.\mathrm{cm}^{-1}\right), \beta$-sheets/strands $\left(1605-1615 \mathrm{~cm}^{-1}, 1616-1621 \mathrm{~cm}^{-1}, 1622-1627 \mathrm{~cm}^{-1}\right.$, and $\left.1628-1637 \mathrm{~cm}^{-1}\right)$ and turns/unordered $\left(1638-1646 \mathrm{~cm}^{-1}, 1647-1655 \mathrm{~cm}^{-1}, 1671-1685 \mathrm{~cm}^{-1}\right.$, and 1686-1696 $\mathrm{cm}^{-1}$ ) secondary structures. ${ }^{63-64}$ The estimated secondary structural contents are presented in Figure 8D. The secondary structures obtained from FTIR results are in general agreement with XRD results. The decrease in crytallinity of SPI/SF hybrid hydrogels with increase in SF content suggests change in secondary structure and solubility of SPI in the 
presence of SF (due to SPI-SF molecular interactions), which could greatly influence their mechanical and degradation properties.
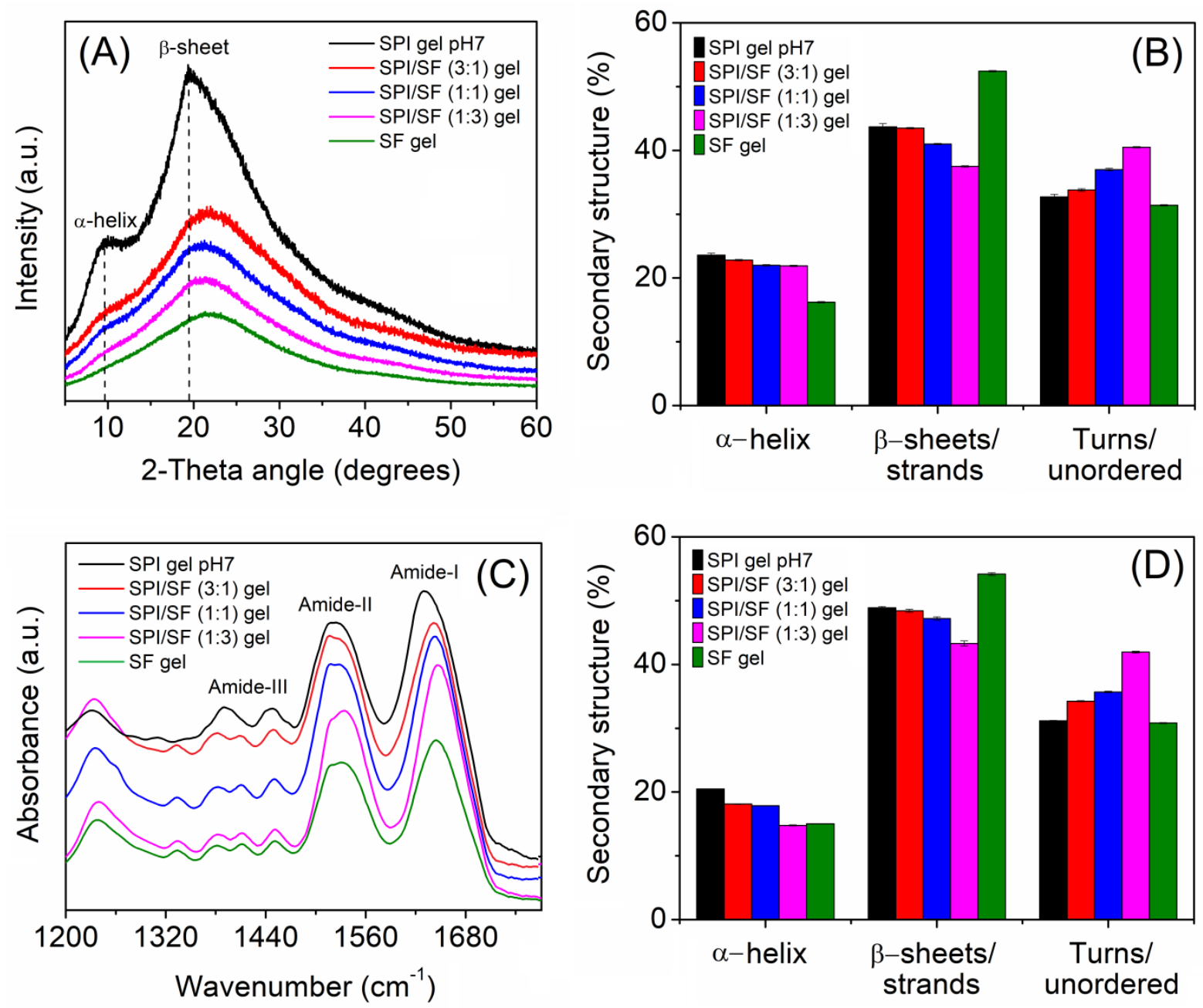

Figure 8. (A) X-ray diffractogram, (B) quantitative secondary structure estimates from XRD data, (C) FTIR spectra, and (D) quantitative secondary structure estimates from FTIR data of SPI/SF hybrid hydrogels compared to pristine SPI and SF hydrogels.

The effect of SF content on the molecular chain mobility of SPI/SF hybrid hydrogels was studied by DSC technique. The measured $T_{g}$ values of fabricated hydrogels (Figure 9) are given in Table 1, where the $T_{g}$ values for pristine SPI and SF hydrogels are in general agreement with literature reports. ${ }^{19,39}$ The SF gel exhibited the lowest $T_{g}\left(\sim 168^{\circ} \mathrm{C}\right)$, whereas the SPI gel pH7 exhibited the highest $\left(\sim 216^{\circ} \mathrm{C}\right)$ amongst the fabricated hydrogels, and therefore has the 
lowest chain mobility. The measured $T_{g}$ of SPI gel $\mathrm{pH} 7$ is similar to that of SPI powder (Figure S2 in Supporting Information), and therefore indicate the SPI gel $\mathrm{pH} 7$ to contain glycinin globules. ${ }^{39}$ The SPI/SF hybrid hydrogels showed $T_{g}$ between that of SPI gel $\mathrm{pH} 7$ and SF gel, which supports miscibility/molecular interaction of macromolecules and co-crosslinking between SPI and SF.
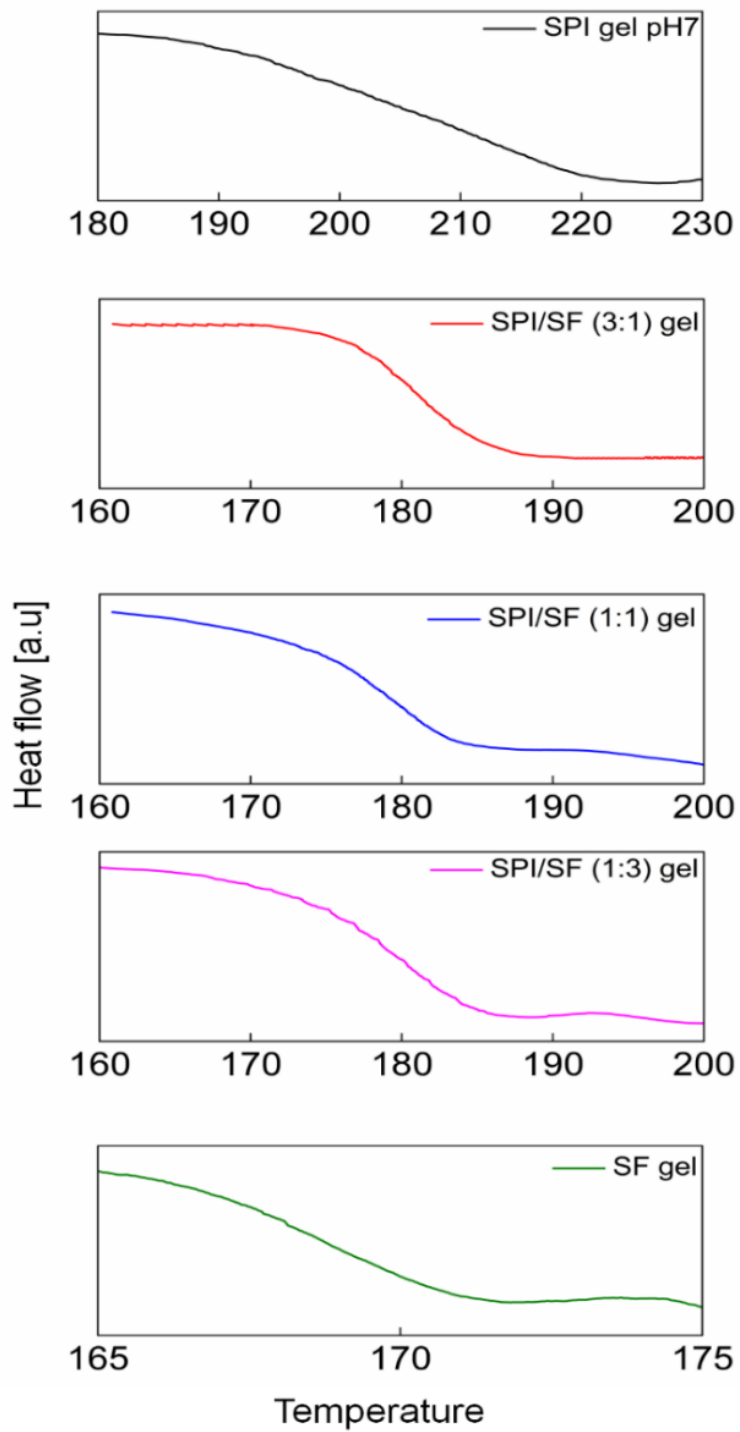

Figure 9. DSC thermogram showing glass transition of SPI/SF hybrid hydrogels compared to pristine SPI and SF hydrogels.

Hierarchical structure of hybrid hydrogels. The effect of SF content on the hierarchical structure (from $2 \mathrm{~nm}$ to $12.5 \mu \mathrm{m}$ ) of the equilibrium $\mathrm{D}_{2} \mathrm{O}$ swollen SPI/SF hybrid hydrogels 
were investigated using SANS and USANS. The combined SANS and USANS curves of fabricated hydrogels (Figure 10A) showed similar distinctive regions as the SPI dispersion at $\mathrm{pH} 7$ (Figure 2A), but now the neutron scattering data extended to even lower- $q$ : starting at the high- $q$ end, there is a high- $q$ Porod region $\left(0.1<q<0.3 \AA^{-1}\right)$, a mid- $q$ Guinier-like region (about $\left.0.003<q<0.1 \AA^{-1}\right)$, a low- $q$ Porod-like region $\left(0.0004<q<0.003 \AA^{-1}\right)$ and a low- $q$ Guinier region $\left(0.000035<q<0.0004 \AA^{-1}\right)$. The Porod slope at high- $q$ of the SPI gel pH7 $(\sim 2.9)$ obtained from power law fit in the high- $q$ region $\left(0.12<\mathrm{q}<0.25 \AA^{-1}\right)$ is the same as that of the SPI dispersion (discussed previously), which signifies that the globular structures in SPI dispersion is conserved in the hydrogel. Conversely, the SF gel showed a Porod slope of $\sim 4$, which can be attributed to hydrophobic domains containing $\beta$-sheet structures (formed by photocrosslinking) that exhibit a sharp interface with the surrounding environment (amorphous protein matrix and/or $\left.\mathrm{D}_{2} \mathrm{O}\right) .{ }^{19,21}$ The $\mathrm{SPI} / \mathrm{SF}$ hybrid hydrogels showed a progressive increase in Porod slope with increase in SF content, which is attributed to an increased contribution from the hydrophobic domains of SF. The mid- $q$ region of the SPI gel exhibits similar features to that of the SPI dispersion (see Kratky plot in Figure 10B), with broad feature at about 0.007 and $0.02 \AA^{-1}$, supporting SPI globulins and their aggregates to be present in the photocrosslinked hydrogel. With increasing SF content, these features become less pronounced, even for the SPI/SF (3:1) hybrid hydrogel, and instead appearance of a shoulder at about $0.085 \AA^{-1}$ becomes more dominant. This may be due to a disruption and decrease in the volume fraction of SPI globulins aggregates (observed in SANS curves of SPI dispersion) and increase in the volume fraction of SF hydrophobic domains. ${ }^{19,}{ }^{21}$ Conversely, the mid- $q$ scattering intensity of SF hydrogel is also contributed by hydrophilic domains containing unordered secondary structures. ${ }^{19,21}$ The observed trends in SANS intensity can be clearly seen from the Kratky plot (Figure 10B). The USANS region (low- $q$ ) shows a strong upturn with power law behavior of $\sim q^{-3.5}$ (low- $q$ Porod-like region) that plateaus at very low- $q$ (low- $q$ 
Guinier region). This feature is characteristic of porous structure (clearly seen in Kratky plot), and is likely to stem from micropores and channels observed in the SEM image of the hydrogels. ${ }^{36}$ Therefore, the observed differences in water uptake of the fabricated hydrogels may be predominantly due to porous microstructure, and their inhomogeneities.
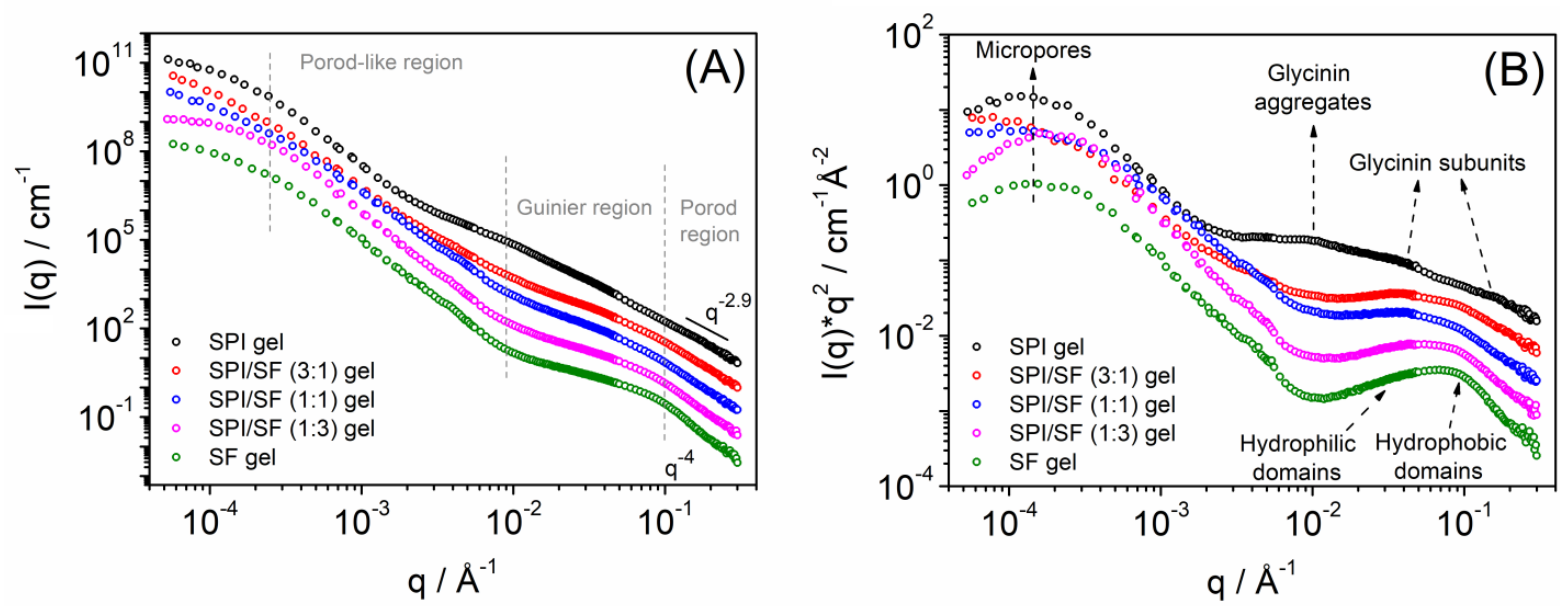

Figure 10. (A) SANS and USANS intensity profile, and (B) Kratky plot of SPI/SF hybrid hydrogels compared to pristine SPI and SF hydrogels.

Viscoelastic properties of hybrid hydrogels. The effect of SF content on the viscoelastic properties of SPI/SF hybrid hydrogels were measured using dynamic rheological experiment in both strain and frequency sweep modes. Figure 11A and Figure 11B show the strain dependency of storage modulus ( $\left.G^{\prime}\right)$ and loss modulus ( $\left.G^{\prime \prime}\right)$ of the fabricated hydrogels, respectively; whereas, Figure 11C and Figure 11D shows the frequency dependent rheological characteristics. The marginal decrease in the modulus of the hydrogels at higher strain $(>>1 \%)$ indicates breakage of the network structure, whereas increase in the modulus at higher frequency indicates increase in mechanical rigidity. ${ }^{56-57}$ The higher value of G' measured at a strain of $0.1 \%$ for SPI gel $\mathrm{pH} 7$ directly implies it to be the stiffest amongst the fabricated hydrogels (Figure 11E). ${ }^{58}$ The SPI/SF hybrid hydrogels demonstrated G' in the order of SPI/SF (3:1) $>$ SPI/SF (1:1) > SPI/SF (1:3). The decrease in stiffness of SPI/SF hybrid hydrogels with 
increase in SF content can be attributed to increase in pore size and order of porous microstructure (Figure 7), increase in water uptake (water acts as a plasticizer) and disruption in the globular structure of SPI in the presence of SF (Figure 10). In SPI/SF (1:1) and SPI/SF (1:3) hybrid hydrogels, SF appears to be the continuous phase with SPI as the dispersed phase with significant role as pore modifiers. Moreover, the observed decrease in tan delta or loss factor (Figure 11F) of these SPI/SF hybrid hydrogels with increase in SF content demonstrates increased elasticity and resilience. ${ }^{65}$ The measured G' value of SPI/SF hybrid hydrogels in the range of $0.2-1.4 \mathrm{kPa}$ is comparable to that of microtubule, ${ }^{66}$ and peptide-heparin ${ }^{67}$ supramolecular hydrogels applied for regenerative medicine. 

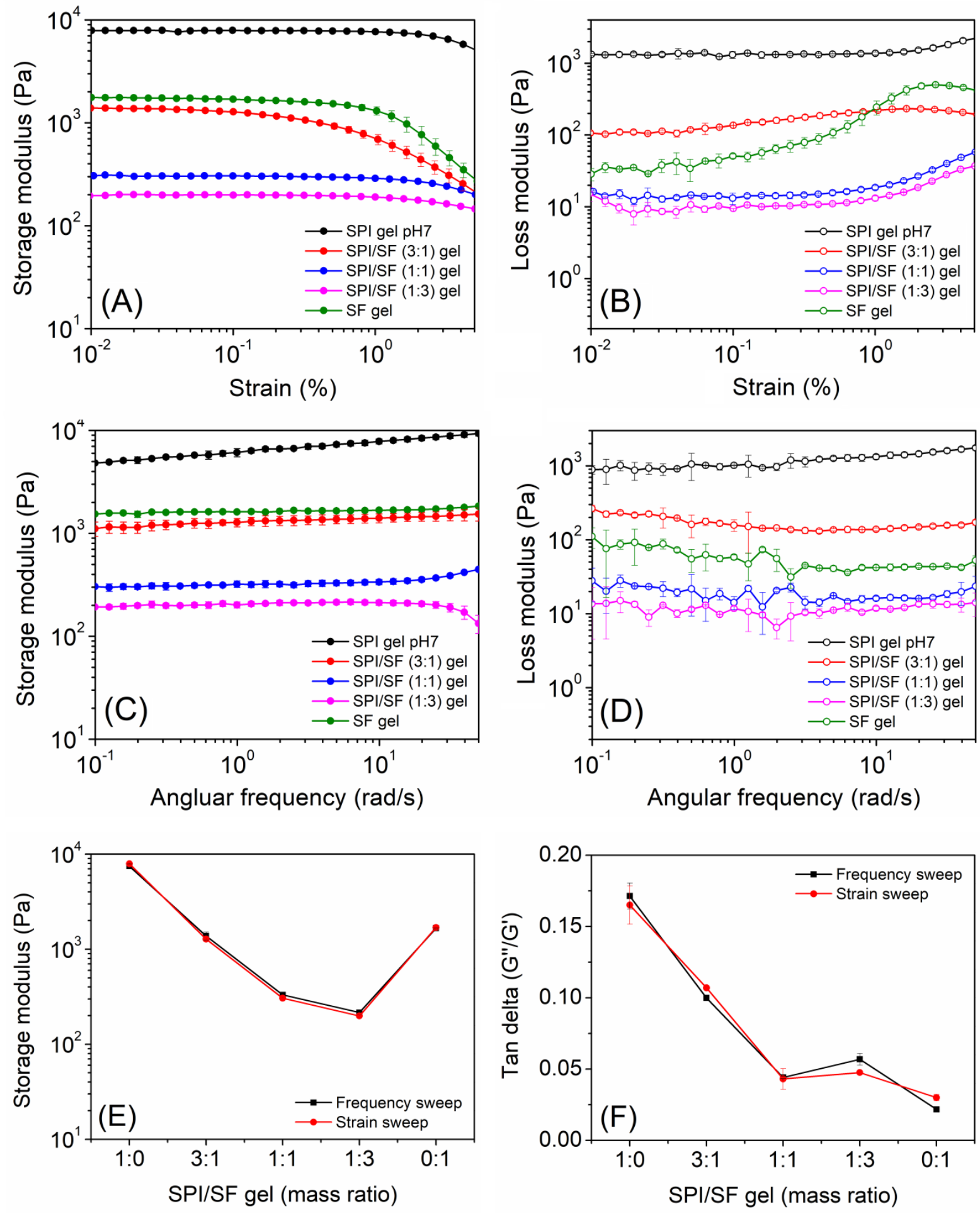

Figure 11. Dynamic viscoelastic properties of SPI/SF hybrid hydrogels compared to pristine SPI and SF gels: (A) and (B) are strain sweep measurements, (C) and (D) are frequency sweep measurements, and (E) and (F) are compares storage modulus and tan delta from both sweeps, respectively. 
Hydrolytic degradation of hybrid hydrogels. Figure 12 shows the effect of SF content on the in vitro hydrolytic degradation behavior of SPI/SF hybrid hydrogels in $10 \mathrm{mM}$ PBS (pH 7.4) over a period of 28 days. The SF gel showed the highest water-resistivity, whereas SPI gel pH7 showed the least amongst the fabricated hydrogels. The higher stability of SF gel in PBS compared to SPI gel $\mathrm{pH} 7$ may be attributed to its higher glycine and alanine amino acid contents and their repeat sequence in primary structure. ${ }^{68}$ The SPI/SF hybrid hydrogels showed improved water-resistivity with increase in SF content. The SPI/SF (3:1), SPI/SF (1:1) and SPI/SF (1:3) hybrid hydrogels showed mass recovery values of $\sim 84 \%, \sim 87 \%$ and $\sim 90 \%$, respectively after 28 days.

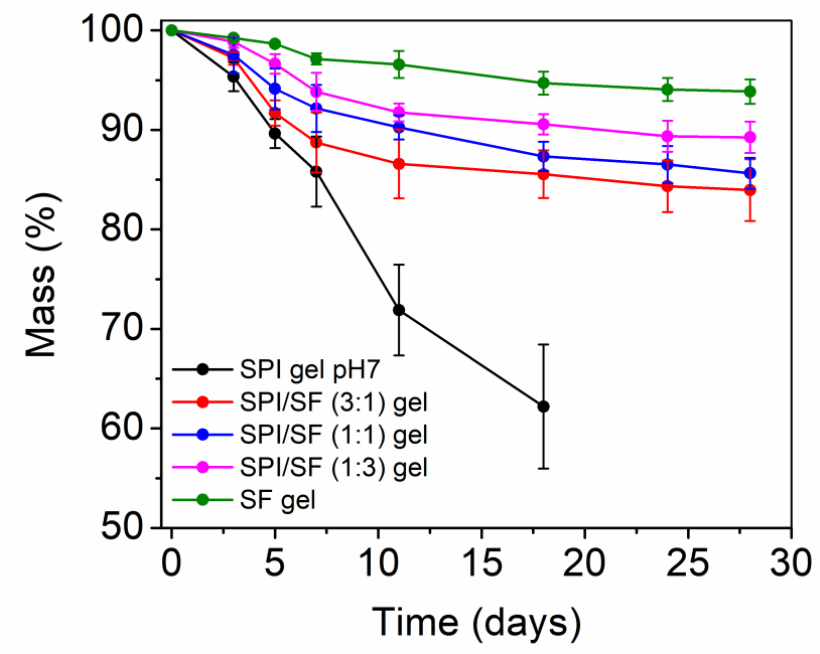

Figure 12. In vitro degradation behavior of SPI/SF hybrid hydrogels compared to pristine SPI and SF gels.

\section{Flow properties of SPI/SF hybrid inks for printability}

To examine the likelihood of printing developed hydrogel systems for tissue engineering application, pristine SPI, pristine SF, and SPI/SF hybrid inks at same protein concentration (15 $\mathrm{wt} \%$ ) used for hydrogel fabrication was assessed using rotational rheology. Figure 13A shows the shear rate dependent apparent viscosity profile of SPI/SF hybrid inks compared to pristine protein inks. It is observed that the pristine SPI ink behaves as a shear thinning fluid (decrease 
in viscosity with increase in shear rate) throughout the experimental condition, whereas the pristine SF ink show shear thinning behavior up to a shear rate of $50 \mathrm{~s}^{-1}$, above which exhibits Newtonian behavior. The plateau region (Newtonian region) of SF ink observed at high shear rates can be attributed to the formation of more ordered structural re-organization of silk fibroin molecules under shear, which restricts the network breakage. ${ }^{69}$ Blending SF with SPI systematically decreased the viscosity of the SPI ink at low shear rates, and initiated the onset of Newtonian behavior (observed for SF ink) at higher shear rates, which shifts to lower shear rates with increase in SF content. The structure of SPI is composed of two major globulins, namely glycinin (11S) and $\beta$-conglycinin (7S) which have different secondary structures including $\alpha$-helix. ${ }^{3}$ On the other hand, SF is dominated by Glycine (43.4 mol\%), known as a helix breaker which could disrupt the SPI structure, ${ }^{62}$ thereby decreasing the viscosity of blends. Therefore, the decrease in viscosity of SPI/SF ink at low shear rates (Shear thinning region) with the increase in SF content can be attributed to the decrease in helix structures, whereas the observed higher viscosity of SPI/SF inks at higher shear rates (Newtonian region) indicate formation of strong interacting (intermolecular interactions between SPI and SF molecules) network which cannot be breached by shear in the maximum tested range. All the inks tested showed shear thinning behavior between a shear rate of 0.01 and $1.0 \mathrm{~s}^{-1}$, which is an important parameter in extrusion-based printing as the viscous ink deforms more slowly which provide good resolution to the final printed gel structure. ${ }^{70}$ Among the tested inks, the pristine SPI exhibited the highest viscosity (at $0.1 \mathrm{~s}^{-1}$ ) followed by SPI/SF (3:1), pristine SF, SPI/SF (1:1) and SPI/SF (1:3), respectively. All the inks exhibited viscosity in the range of $0.06-8.0 \times 10^{3}$ Pa.s at low shear rates of $0.01-0.1 \mathrm{~s}^{-1}$, which is in good agreement with values previous reported for bioinks used for 3D printing. ${ }^{71}$ Moreover, the lower viscosity of SPI/SF hybrid inks, and the non-toxic and minimally inflammatory nature of ruthenium-persulfate cross-linking system used in this study could be potentially used as bioinks for printing cells. ${ }^{47}$, 
${ }^{70}$ In addition to shear thinning, structure recovery is also an important factor to be considered for $3 \mathrm{D}$ printing to determine the quality/resolution of printed construct. Therefore, we studied the structural recovery of protein inks by varying the shear rates (low-high-low) with respect to time, as shown in Figure 13B. It was observed that all the inks have an excellent recovering ability (in a few seconds), and the amount of recovery varied with the change in SF content. The percentage recovery was calculated by the ratio of the stabilized (plateau) viscosity after and before shear rate of $50 \mathrm{~s}^{-1}$, and the prepared inks demonstrated the percentage recovery of $75.34 \%, 83.16 \%, 88.57 \%$ and $94.41 \%$ for SPI, SPI/SF (3:1), SPI/SF (1:1) and SPI/SF (1:3), respectively. The calculated values elucidate that the structural recovery of SPI/SF ink increases with the increase in SF content, favoring 3D printing applications. Therefore, the observed shear thinning and recovering behavior support printing potential of complex structures using the prepared pristine and hybrid protein inks. Overall, it is clearly observed that the presence of SF strongly influences the SPI by disrupting and making network with shear as a variable. An in depth investigation of 3D printing of different types of hydrogel structures using the prepared inks and in vitro cell viability/proliferation of fabricated hydrogels will be reported in the future for tissue engineering applications, and is beyond the scope of this article.
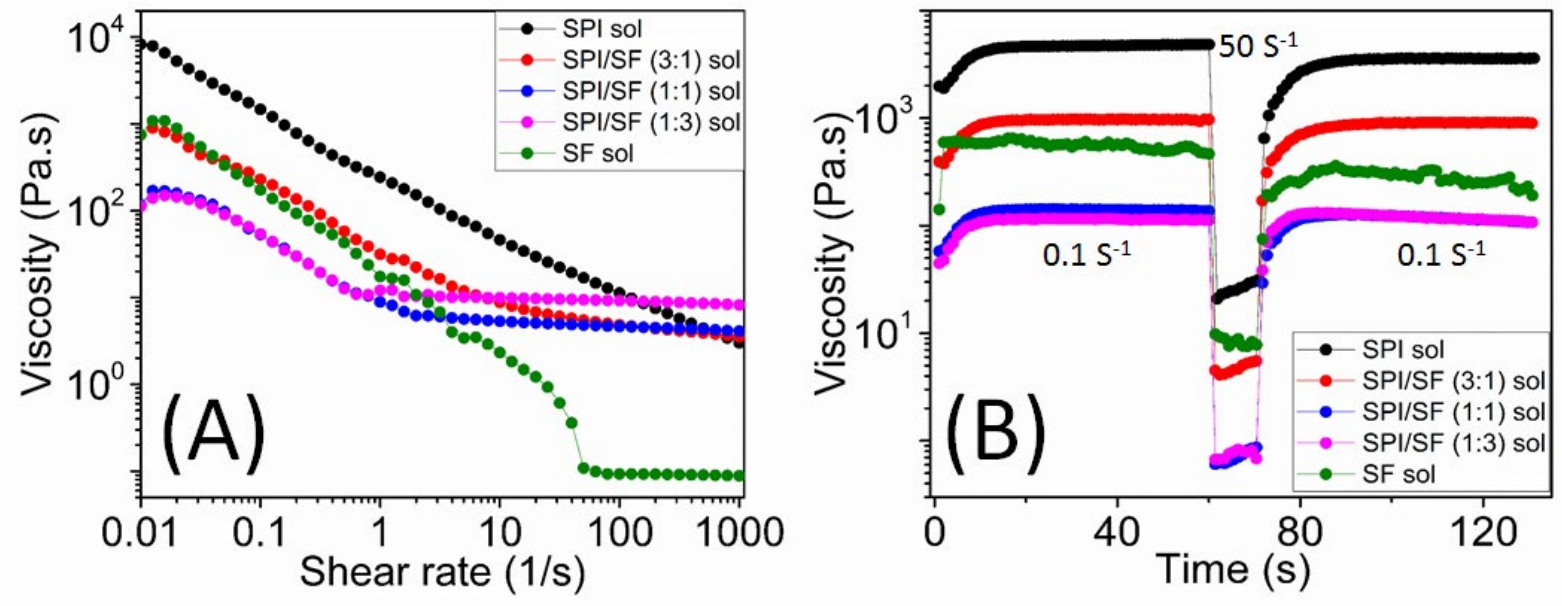
Figure 13. Rheological properties of SPI/SF hybrid inks compared to pristine SPI and SF inks (sol): (A) shear rate dependent viscosity profile (at different weight ratios), and (B) viscosity recovery profile.

\section{CONCLUSIONS}

In summary, pristine SPI hydrogels and co-crosslinked SPI/SF hybrid hydrogels of tunable morphology, porosity and viscoelastic characteristics have been successfully fabricated by a fast and facile photocrosslinking method. The SPI hydrogel photocrosslinked at $\mathrm{pH} 7$ exhibited a particulate microstructure, higher crosslink density, crystallinity, shear storage modulus and tan delta, and water-resistivity compared to SPI hydrogel photocrosslinked at pH 12. Conversely, the SPI hydrogel photocrosslinked at $\mathrm{pH} 12$ exhibited well-ordered porous microstructure and higher water uptake. The difference in observed microstructure of SPI hydrogels is attributed to the difference in their secondary structure (11S glycinin and aggregates at $\mathrm{pH} 7$, whereas $7 \mathrm{~S}$ glycinin at $\mathrm{pH} 12$ ) due to $\mathrm{pH}$ and its perpetuity during crosslinking. The obtained mechanical and water-resistant properties of the photocrosslinked SPI hydrogels are superior to those reported by thermal treatment, pressure treatment, saltinduced cold-setting and enzymatic crosslinking. Moreover, it is evident that the addition of SF to SPI disrupts the secondary structural organization of SPI. Progressive increase in the SF content of the SPI/SF hybrid hydrogels increased the crosslink density, porosity, molecular chain mobility, water uptake and resistivity, whereas decreased the crystallinity, shear storage modulus and tan delta. The optimized SPI/SF hybrid hydrogels are sustainable, robust and biocompatible with tunable mechanical, rheological and bio-degradation properties, and hence have great potential as a multifunctional material for various biomedical applications. Moreover, the shear thinning and recovery nature of pristine SPI ink and SPI/SF hybrid inks along with rapid gelation kinetics of the crosslinking mechanism have the potential to facilitate 
a noble platform to develop 3D printable photocrosslinked SPI-based hybrid hydrogel systems for tissue engineering applications.

\section{Author Contributions}

The manuscript was written through contributions of all authors. All authors have given approval to the final version of the manuscript.

\section{Notes}

The authors declare no competing financial interest.

\section{ACKNOWLEDGMENTS}

This work was financially supported by the Australian Research Council (ARC) through Discovery research grant (DP160101267). Access to the SANS and USANS facility at the ACNS was supported through ANSTO beam time award (P5772 \& P5871). The authors acknowledge the facilities, and the scientific and technical assistance, of the Australian Microscopy \& Microanalysis Research Facility at the Adelaide Microscopy, University of Adelaide. This work benefited from the use of SasView application, originally developed under NSF award DMR-0520547. SasView contains code developed with funding from the European Union's Horizon 2020 research and innovation programme under the SINE2020 project, grant agreement No 654000 .

\section{REFERENCES}

(1) Jonker, A. M.; Löwik, D. W. P. M.; van Hest, J. C. M., Peptide- and Protein-Based Hydrogels. Chemistry of Materials 2012, 24 (5), 759-773.

(2) Song, F.; Tang, D.-L.; Wang, X.-L.; Wang, Y.-Z., Biodegradable Soy Protein IsolateBased Materials: A Review. Biomacromolecules 2011, 12 (10), 3369-3380.

(3) Jiang, J.; Xiong, Y. L.; Chen, J., pH Shifting Alters Solubility Characteristics and Thermal Stability of Soy Protein Isolate and Its Globulin Fractions in Different $\mathrm{pH}$, Salt 
Concentration, and Temperature Conditions. Journal of Agricultural and Food Chemistry 2010, 58 (13), 8035-8042.

(4) Berghout, J. A. M.; Boom, R. M.; van der Goot, A. J., Understanding the differences in gelling properties between lupin protein isolate and soy protein isolate. Food Hydrocolloids 2015, 43, 465-472.

(5) Molina, E.; Defaye, A. B.; Ledward, D. A., Soy protein pressure-induced gels. Food Hydrocolloids 2002, 16 (6), 625-632.

(6) Maltais, A.; Remondetto, G. E.; Gonzalez, R.; Subirade, M., Formation of soy protein isolate cold-set gels: protein and salt effects. Journal of food science 2005, 70 (1).

(7) Renkema, J. M. S.; van Vliet, T., Heat-Induced Gel Formation by Soy Proteins at Neutral pH. Journal of Agricultural and Food Chemistry 2002, 50 (6), 1569-1573.

(8) Qin, X.-S.; Luo, S.-Z.; Cai, J.; Zhong, X.-Y.; Jiang, S.-T.; Zhao, Y.-Y.; Zheng, Z., Transglutaminase-induced gelation properties of soy protein isolate and wheat gluten mixtures with high intensity ultrasonic pretreatment. Ultrasonics Sonochemistry 2016, 31, 590-597.

(9) Tian, K.; Shao, Z.; Chen, X., Natural Electroactive Hydrogel from Soy Protein Isolation. Biomacromolecules 2010, 11 (12), 3638-3643.

(10) Caillard, R.; Remondetto, G. E.; Mateescu, M. A.; Subirade, M., Characterization of Amino Cross-Linked Soy Protein Hydrogels. Journal of Food Science 2008, 73 (5), C283C291.

(11) Song, F.; Zhang, L.-M., Gelation Modification of Soy Protein Isolate by a Naturally Occurring Cross-Linking Agent and Its Potential Biomedical Application. Industrial \& Engineering Chemistry Research 2009, 48 (15), 7077-7083.

(12) Liu, J.; Li, Z.; Lin, Q.; Jiang, X.; Yao, J.; Yang, Y.; Shao, Z.; Chen, X., A Robust, Resilient, and Multi-Functional Soy Protein-Based Hydrogel. ACS Sustainable Chemistry \& Engineering 2018, 6 (11), 13730-13738.

(13) Rahman, M. M.; Netravali, A. N.; Tiimob, B. J.; Rangari, V. K., Bioderived "Green" Composite from Soy Protein and Eggshell Nanopowder. ACS Sustainable Chemistry \& Engineering 2014, 2 (10), 2329-2337.

(14) Song, W.; Xin, J.; Zhang, J., One-pot synthesis of soy protein (SP)-poly(acrylic acid) (PAA) superabsorbent hydrogels via facile preparation of SP macromonomer. Industrial Crops and Products 2017, 100, 117-125.

(15) Iatridis, J. C.; Setton, L. A.; Weidenbaum, M.; Mow, V. C., The viscoelastic behavior of the non-degenerate human lumbar nucleus pulposus in shear. Journal of Biomechanics 1997, 30 (10), 1005-1013. 
(16) Whittaker, J. L.; Choudhury, N. R.; Dutta, N. K.; Zannettino, A., Facile and rapid ruthenium mediated photo-crosslinking of Bombyx mori silk fibroin. Journal of Materials Chemistry B 2014, 2 (37), 6259-6270.

(17) Whittaker, J. L.; Dutta, N. K.; Elvin, C. M.; Choudhury, N. R., Fabrication of highly elastic resilin/silk fibroin based hydrogel by rapid photo-crosslinking reaction. Journal of Materials Chemistry B 2015, 3 (32), 6576-6579.

(18) Whittaker, J. L.; Dutta, N. K.; Zannettino, A.; Choudhury, N. R., Engineering DN hydrogels from regenerated silk fibroin and poly(N-vinylcaprolactam). Journal of Materials Chemistry B 2016, 4 (33), 5519-5533.

(19) Balu, R.; Reeder, S.; Knott, R.; Mata, J.; de Campo, L.; Dutta, N. K.; Choudhury, N. R., Tough Photocrosslinked Silk Fibroin/Graphene Oxide Nanocomposite Hydrogels. Langmuir 2018, 34 (31), 9238-9251.

(20) Balu, R.; Mata, J. P.; Knott, R.; Elvin, C. M.; Hill, A. J.; Choudhury, N. R.; Dutta, N. K., Effects of Crowding and Environment on the Evolution of Conformational Ensembles of the Multi-Stimuli-Responsive Intrinsically Disordered Protein, Rec1-Resilin: A Small-Angle Scattering Investigation. The Journal of Physical Chemistry B 2016, 120 (27), 6490-6503.

(21) Whittaker, J. L.; Balu, R.; Knott, R.; de Campo, L.; Mata, J. P.; Rehm, C.; Hill, A. J.; Dutta, N. K.; Roy Choudhury, N., Structural evolution of photocrosslinked silk fibroin and silk fibroin-based hybrid hydrogels: A small angle and ultra-small angle scattering investigation. International Journal of Biological Macromolecules 2018, 114, 998-1007.

(22) Schaefer, D. W.; Agamalian, M. M., Ultra-small-angle neutron scattering: a new tool for materials research. Current Opinion in Solid State and Materials Science 2004, 8 (1), 3947.

(23) M, V. P.; Nazarenko, O., Soy Protein-Based Blends, Composites and Nanocomposites. Wiley: 2017.

(24) Herrero, A. M.; Jiménez-Colmenero, F.; Carmona, P., Elucidation of structural changes in soy protein isolate upon heating by Raman spectroscopy. International Journal of Food Science \& Technology 2009, 44 (4), 711-717.

(25) Sokolova, A.; Christoforidis, J.; Eltobaji, A.; Barnes, J.; Darmann, F.; Whitten, A. E.; de Campo, L., BILBY: Time-of-Flight Small Angle Scattering Instrument. Neutron News 2016, 27 (2), 9-13.

(26) Wood, K.; Mata, J. P.; Garvey, C. J.; Wu, C.-M.; Hamilton, W. A.; Abbeywick, P.; Bartlett, D.; Bartsch, F.; Baxter, P.; Booth, N.; Brown, W.; Christoforidis, J.; Clowes, D.; d'Adam, T.; Darmann, F.; Deura, M.; Harrison, S.; Hauser, N.; Horton, G.; Federici, D.; 
Franceschini, F.; Hanson, P.; Imamovic, E.; Imperia, P.; Jones, M.; Kennedy, S.; Kim, S.; Lam, T.; Lee, W. T.; Lesha, M.; Mannicke, D.; Noakes, T.; Olsen, S. R.; Osborn, J. C.; Penny, D.; Perry, M.; Pullen, S. A.; Robinson, R. A.; Schulz, J. C.; Xiong, N.; Gilbert, E. P., QUOKKA, the pinhole small-angle neutron scattering instrument at the OPAL Research Reactor, Australia: design, performance, operation and scientific highlightsThis article will form part of a virtual special issue on advanced neutron scattering instrumentation, marking the 50th anniversary of the journal. Journal of Applied Crystallography 2018, 51 (2), 294-314.

(27) Kline, S. R., Reduction and analysis of SANS and USANS data using IGOR Pro. Journal of applied crystallography 2006, 39 (6), 895-900.

(28) Konarev, P. V.; Volkov, V. V.; Sokolova, A. V.; Koch, M. H.; Svergun, D. I., PRIMUS: a Windows PC-based system for small-angle scattering data analysis. Journal of applied crystallography 2003, 36 (5), 1277-1282.

(29) Rehm, C.; Brûlé, A.; Freund, A. K.; Kennedy, S. J., Kookaburra: the ultra-small-angle neutron scattering instrument at OPAL. Journal of Applied Crystallography 2013, 46 (6), 16991704.

(30) Chronakis, I. S., Network formation and viscoelastic properties of commercial soy protein dispersions: effect of heat treatment, $\mathrm{pH}$ and calcium ions. Food Research International 1996, 29 (2), 123-134.

(31) Badley, R. A.; Atkinson, D.; Hauser, H.; Oldani, D.; Green, J. P.; Stubbs, J. M., The structure, physical and chemical properties of the soy bean protein glycinin. Biochimica et Biophysica Acta (BBA) - Protein Structure 1975, 412 (2), 214-228.

(32) Vu Huu, T.; Shibasaki, K., Major proteins of soybean seeds. Subunit structure of .beta.conglycinin. Journal of Agricultural and Food Chemistry 1978, 26 (3), 692-695.

(33) Bakarich, S. E.; Panhuis, M. i. h.; Beirne, S.; Wallace, G. G.; Spinks, G. M., Extrusion printing of ionic-covalent entanglement hydrogels with high toughness. Journal of Materials Chemistry B 2013, 1 (38), 4939-4946.

(34) Bakarich, S. E.; Panhuis, M. i. h.; Beirne, S.; Wallace, G. G.; Spinks, G. M., Extrusion printing of ionic--covalent entanglement hydrogels with high toughness. Journal of Materials Chemistry B 2013, 1 (38), 4939-4946.

(35) Yang, F.; Tadepalli, V.; Wiley, B. J., 3D Printing of a Double Network Hydrogel with a Compression Strength and Elastic Modulus Greater than those of Cartilage. ACS Biomaterials Science \& Engineering 2017, 3 (5), 863-869.

(36) Feigin, L. A.; Svergun, D. I., Structure Analysis by Small-Angle X-Ray and Neutron Scattering. Springer US: 2013. 
(37) Nagy, B.; Tóth, A.; Savina, I.; Mikhalovsky, S.; Mikhalovska, L.; Grillo, I.; Geissler, E.; László, K., Small angle neutron scattering study of globular proteins confined in porous carbons. Carbon 2016, 106, 142-151.

(38) Guo, J.; Yang, X.-Q.; He, X.-T.; Wu, N.-N.; Wang, J.-M.; Gu, W.; Zhang, Y.-Y., Limited Aggregation Behavior of $\beta$-Conglycinin and Its Terminating Effect on Glycinin Aggregation during Heating at pH 7.0. Journal of Agricultural and Food Chemistry 2012, 60 (14), 3782-3791.

(39) Morales, A.; Kokini, J. L., Glass Transition of Soy Globulins Using Differential Scanning Calorimetry and Mechanical Spectrometry. Biotechnology Progress 1997, 13 (5), 624-629.

(40) Lakemond, C. M. M.; de Jongh, H. H. J.; Hessing, M.; Gruppen, H.; Voragen, A. G. J., Soy Glycinin: Influence of $\mathrm{pH}$ and Ionic Strength on Solubility and Molecular Structure at Ambient Temperatures. Journal of Agricultural and Food Chemistry 2000, 48 (6), 1985-1990.

(41) Adachi, M.; Kanamori, J.; Masuda, T.; Yagasaki, K.; Kitamura, K.; Mikami, B.; Utsumi, S., Crystal structure of soybean 11S globulin: Glycinin A3B4 homohexamer. Proceedings of the National Academy of Sciences 2003, 100 (12), 7395-7400.

(42) Nishinari, K.; Fang, Y.; Guo, S.; Phillips, G. O., Soy proteins: A review on composition, aggregation and emulsification. Food Hydrocolloids 2014, 39, 301-318.

(43) Hammouda, B., A new Guinier-Porod model. Journal of Applied Crystallography 2010, 43 (4), 716-719.

(44) Pizones Ruiz-Henestrosa, V. M.; Martinez, M. J.; Patino, J. M. R.; Pilosof, A. M. R., A Dynamic Light Scattering Study on the Complex Assembly of Glycinin Soy Globulin in Aqueous Solutions. Journal of the American Oil Chemists' Society 2012, 89 (7), 1183-1191.

(45) Martin, A. H.; Bos, M. A.; van Vliet, T., Interfacial rheological properties and conformational aspects of soy glycinin at the air/water interface. Food Hydrocolloids 2002, 16 (1), 63-71.

(46) Svergun, D. I.; Koch, M. H. J.; Timmins, P. A.; May, R. P., Small Angle X-Ray and Neutron Scattering from Solutions of Biological Macromolecules. OUP Oxford: 2013.

(47) Bjork, J. W.; Johnson, S. L.; Tranquillo, R. T., Ruthenium-catalyzed photo crosslinking of fibrin-based engineered tissue. Biomaterials 2011, 32 (10), 2479-2488.

(48) Brahatheeswaran Dhandayuthapani; Yasuhiko Yoshida; Toru Maekawa; Kumar, D. S., Polymeric Scaffolds in Tissue Engineering Application: A Review. International Journal of Polymer Science 2011, 2011. 
(49) Zhang, J.; Mungara, P.; Jane, J., Mechanical and thermal properties of extruded soy protein sheets. Polymer 2001, 42 (6), 2569-2578.

(50) Liu, Y.; Cui, Y., Preparation and properties of temperature-sensitive soy protein/poly(N-isopropylacrylamide) interpenetrating polymer network hydrogels. Polymer International 2011, 60 (7), 1117-1122.

(51) Chen, J.; Chen, X.; Zhu, Q.; Chen, F.; Zhao, X.; Ao, Q., Determination of the domain structure of the $7 \mathrm{~S}$ and $11 \mathrm{~S}$ globulins from soy proteins by XRD and FTIR. Journal of the Science of Food and Agriculture 2012, 93 (7), 1687-1691.

(52) Xia, C.; Wang, L.; Dong, Y.; Zhang, S.; Shi, S. Q.; Cai, L.; Li, J., Soy protein isolatebased films cross-linked by epoxidized soybean oil. RSC Advances 2015, 5 (101), 8276582771.

(53) Drummy, L. F.; Phillips, D. M.; Stone, M. O.; Farmer, B. L.; Naik, R. R., Thermally Induced $\alpha$-Helix to $\beta$-Sheet Transition in Regenerated Silk Fibers and Films. Biomacromolecules 2005, 6 (6), 3328-3333.

(54) Li, Y.-Q., Structure Changes of Soybean Protein Isolates by Pulsed Electric Fields. Physics Procedia 2012, 33, 132-137.

(55) Lefèvre, T.; Rousseau, M.-E.; Pézolet, M., Protein Secondary Structure and Orientation in Silk as Revealed by Raman Spectromicroscopy. Biophysical Journal 2007, 92 (8), 28852895.

(56) Zuidema, J. M.; Rivet, C. J.; Gilbert, R. J.; Morrison, F. A., A protocol for rheological characterization of hydrogels for tissue engineering strategies. Journal of Biomedical Materials Research Part B: Applied Biomaterials 2013, 102 (5), 1063-1073.

(57) Deshpande, A. P., Oscillatory Shear Rheology for Probing Nonlinear Viscoelasticity of Complex Fluids: Large Amplitude Oscillatory Shear. In Rheology of Complex Fluids, Springer New York: New York, NY, 2010, pp 87-110.

(58) De Leon Rodriguez, L. M.; Hemar, Y.; Cornish, J.; Brimble, M. A., Structuremechanical property correlations of hydrogel forming [small beta]-sheet peptides. Chemical Society Reviews 2016, 45 (17), 4797-4824.

(59) Chien, K. B.; Chung, E. J.; Shah, R. N., Investigation of soy protein hydrogels for biomedical applications: Materials characterization, drug release, and biocompatibility. Journal of Biomaterials Applications 2013, 28 (7), 1085-1096.

(60) Chien, K. B.; Shah, R. N., Novel soy protein scaffolds for tissue regeneration: Material characterization and interaction with human mesenchymal stem cells. Acta Biomaterialia 2012, $8(2), 694-703$. 
(61) Kundu, J.; Poole-Warren, L. A.; Martens, P.; Kundu, S. C., Silk fibroin/poly(vinyl alcohol) photocrosslinked hydrogels for delivery of macromolecular drugs. Acta Biomaterialia 2012, $8(5), 1720-1729$.

(62) Imai, K.; Mitaku, S., Mechanisms of secondary structure breakers in soluble proteins. BIOPHYSICS 2005, 1, 55-65.

(63) Wang, C.; Jiang, L.; Wei, D.; Li, Y.; Sui, X.; Wang, Z.; Li, D., Effect of Secondary Structure determined by FTIR Spectra on Surface Hydrophobicity of Soybean Protein Isolate. Procedia Engineering 2011, 15, 4819-4827.

(64) Hu, X.; Kaplan, D.; Cebe, P., Determining Beta-Sheet Crystallinity in Fibrous Proteins by Thermal Analysis and Infrared Spectroscopy. Macromolecules 2006, 39 (18), 6161-6170.

(65) Yan, C.; Pochan, D. J., Rheological properties of peptide-based hydrogels for biomedical and other applications. Chemical Society Reviews 2010, 39 (9), 3528-3540.

(66) Sano, K.-I.; Kawamura, R.; Tominaga, T.; Nakagawa, H.; Oda, N.; Ijiro, K.; Osada, Y., Thermoresponsive Microtubule Hydrogel with High Hierarchical Structure. Biomacromolecules 2011, 12 (5), 1409-1413.

(67) Wieduwild, R.; Tsurkan, M.; Chwalek, K.; Murawala, P.; Nowak, M.; Freudenberg, U.; Neinhuis, C.; Werner, C.; Zhang, Y., Minimal Peptide Motif for Non-covalent PeptideHeparin Hydrogels. Journal of the American Chemical Society 2013, 135 (8), 2919-2922.

(68) Zhou, C.-Z.; Confalonieri, F.; Jacquet, M.; Perasso, R.; Li, Z.-G.; Janin, J., Silk fibroin: Structural implications of a remarkable amino acid sequence. Proteins: Structure, Function, and Bioinformatics 2001, 44 (2), 119-122.

(69) Xie, F.; Zhang, H.; Shao, H.; Hu, X., Effect of shearing on formation of silk fibers from regenerated Bombyx mori silk fibroin aqueous solution. International Journal of Biological Macromolecules 2006, 38 (3), 284-288.

(70) Donderwinkel, I.; van Hest, J. C. M.; Cameron, N. R., Bio-inks for 3D bioprinting: recent advances and future prospects. Polymer Chemistry 2017, 8 (31), 4451-4471.

(71) Kyle, S.; Jessop, Z. M.; Al-Sabah, A.; Whitaker, I. S., 'Printability' of Candidate Biomaterials for Extrusion Based 3D Printing: State-of-the-Art. Advanced Healthcare Materials 2017, 6 (16), 1700264. 


\section{SUPPORTING INFORMATION}

Table S1. Amino acid composition of soy protein isolate (SPI) and silk fibroin (SF).

\begin{tabular}{|c|c|c|c|c|}
\hline \multirow{2}{*}{$\begin{array}{l}\text { Amino acid } \\
\text { residue }\end{array}$} & \multirow{2}{*}{ Amino acid } & \multirow{2}{*}{ Symbol } & \multicolumn{2}{|c|}{ Mol \% } \\
\hline & & & $S P I^{*}$ & $S F^{1}$ \\
\hline \multirow{9}{*}{ 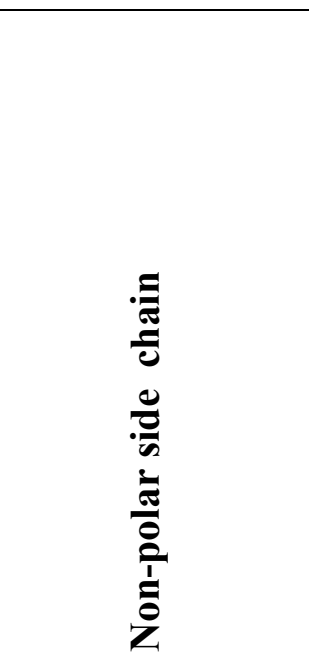 } & Glycine & Gly/G & 4.1 & 43.4 \\
\hline & Alanine & Ala/A & 4.1 & 27.6 \\
\hline & Valine & $\mathrm{Val} / \mathrm{V}$ & 4.7 & 2.37 \\
\hline & Leucine & Leu/L & 7.8 & 0.7 \\
\hline & Isoleucine & Ile/I & 4.8 & 0.8 \\
\hline & Methonine & Met/M & 1.3 & 0.2 \\
\hline & Proline & Pro/P & 5.1 & 0.8 \\
\hline & Phenylalaline & Phe/F & 5.2 & 0.1 \\
\hline & Tryptophan & Try/W & 1.4 & 0.7 \\
\hline \multicolumn{2}{|l|}{ Total nonpolar } & & 38.5 & 76.7 \\
\hline \multirow{6}{*}{ 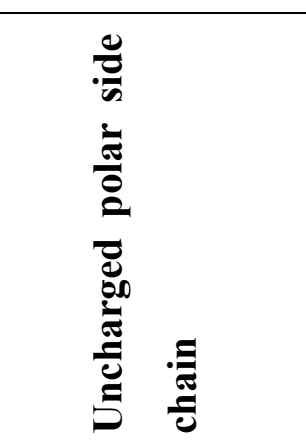 } & Serine & $\mathrm{Ser} / \mathrm{S}$ & 5.1 & 10.4 \\
\hline & Threonine & $\mathrm{Thr} / \mathrm{T}$ & 3.6 & 0.9 \\
\hline & Aspargine & $\mathrm{Asn} / \mathrm{N}$ & - & 1.1 \\
\hline & Glutamine & $\mathrm{Gln} / \mathrm{Q}$ & - & - \\
\hline & Tyrosine & Tyr/Y & 3.7 & 5.6 \\
\hline & Cysteine & $\mathrm{Cys} / \mathrm{C}$ & 1.3 & 0.1 \\
\hline \multicolumn{2}{|c|}{ Total uncharged polar } & & $\begin{array}{ll}13.7 \\
\end{array}$ & 18.1 \\
\hline \multirow{5}{*}{ 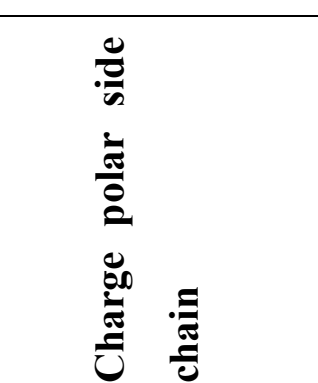 } & Lysine & Lys/K & 6.2 & 0.2 \\
\hline & Arginine & $\operatorname{Arg} / \mathrm{R}$ & 7.7 & 1.1 \\
\hline & Histidine & $\mathrm{His} / \mathrm{H}$ & 2.5 & 0.1 \\
\hline & Aspartic acid & Asp/D & 11.6 & 1.6 \\
\hline & Glutamic acid & $\mathrm{Glu} / \mathrm{E}$ & 19.2 & 1.8 \\
\hline \multicolumn{2}{|c|}{ Total Charged Polar Side Chain } & & 47.2 & 4.8 \\
\hline \multicolumn{2}{|l|}{ Total } & & 100.0 & 100.0 \\
\hline
\end{tabular}

*Supplied by ADM Australia. 


\section{Estimation of SPI dispersion flow parameters:}

The flow parameters of SPI dispersions were obtained by fitting power law function to apparent viscosity vs shear rate data using the curve expert software, ${ }^{2}$ as shown in Figure S1.
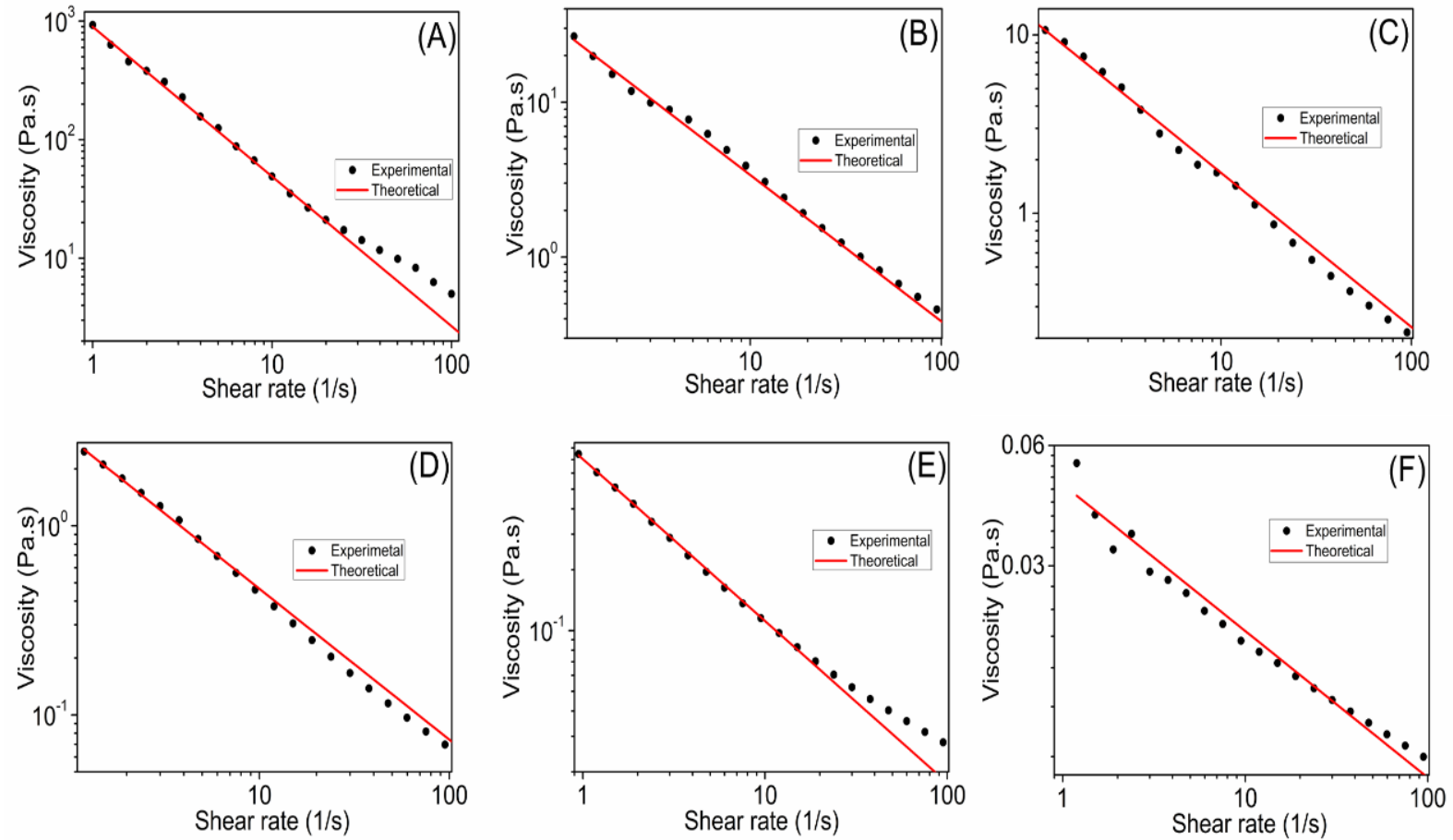

Figure S1. Experimental and power law fit of apparent viscosity vs shear rate data of SPI dispersion at (A) $15 \mathrm{wt} \%$, (B) $12.5 \mathrm{wt} \%$, (C) $10 \mathrm{wt} \%$, (D) $8 \mathrm{wt} \%$, (E) $6 \mathrm{wt} \%$, and (F) $4 \mathrm{wt} \%$ concentration.

Table S2: Estimated SPI dispersion flow parameters.

\begin{tabular}{|c|c|c|c|}
\hline SPI conc. $(\mathbf{w t} \%)$ & $\mathbf{K}$ & $\mathbf{n}$ & $\mathbf{R}^{\mathbf{2}}$ \\
\hline $\mathbf{4}$ & $0.04 \pm 0.001$ & $0.63 \pm 0.016$ & 0.9689 \\
\hline $\mathbf{6}$ & $0.70 \pm 0.004$ & $0.19 \pm 0.008$ & 0.9985 \\
\hline $\mathbf{8}$ & $2.91 \pm 0.025$ & $0.20 \pm 0.009$ & 0.9985 \\
\hline $\mathbf{1 0}$ & $12.36 \pm 0.146$ & $0.13 \pm 0.016$ & 0.9961 \\
\hline $\mathbf{1 2 . 5}$ & $29.81 \pm 0.55$ & $0.056 \pm 0.023$ & 0.9938 \\
\hline $\mathbf{1 5}$ & $896.50 \pm 11.70$ & $0.0262 \pm 0.02$ & 0.9952 \\
\hline
\end{tabular}


Thermal analysis of SPI powder:
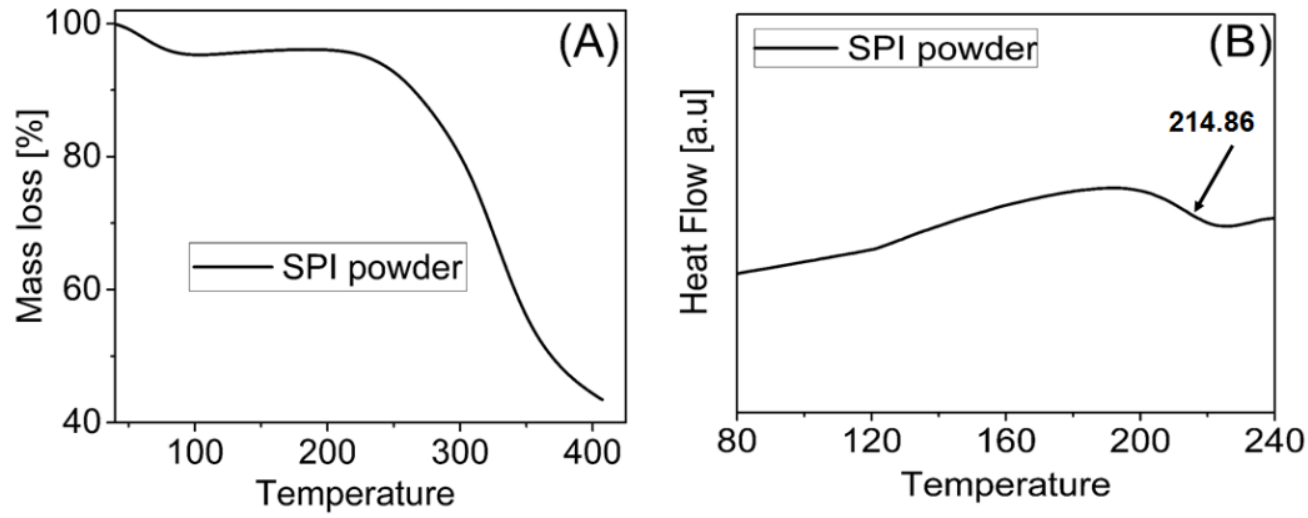

Figure S2. (A) Thermogravimetric analysis (TGA), and (B) Differential scanning calorimetry (DSC) thermograms of SPI powder.

\section{Mechanism of photocrosslinking:}

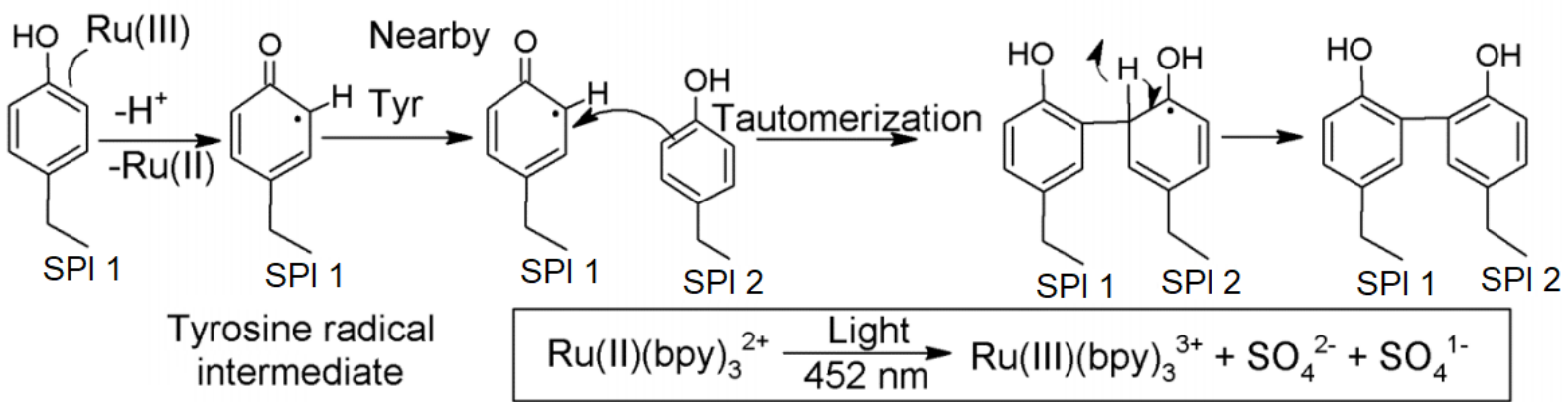

Figure S3. Photocrosslinking reaction schematic. 


\section{Estimation of fabricated hydrogel secondary structure:}

The secondary structure of fabricated hydrogels were obtained by deconvoluting X-ray diffractogram, Raman and Fourier transform infrared (FTIR) spectra using MagicPlot software (https://magicplot.com/) with Gaussian curve fitting, ${ }^{3-4}$ as shown in Figure S4-S7.
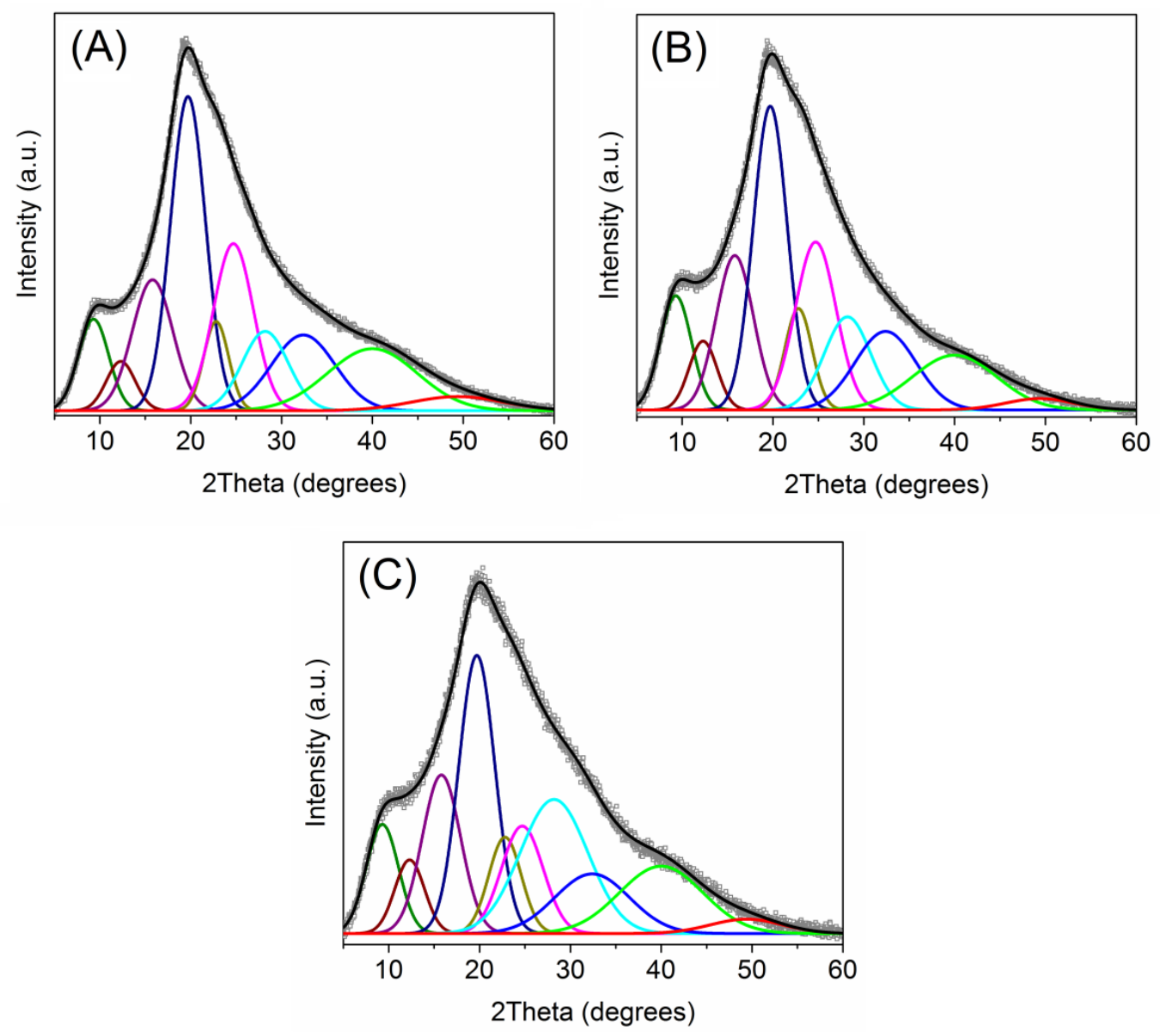

Figure S4. Deconvoluted X-ray diffractogram of (A) SPI, (B) SPI gel pH7, and (C) SPI gel pH12. 

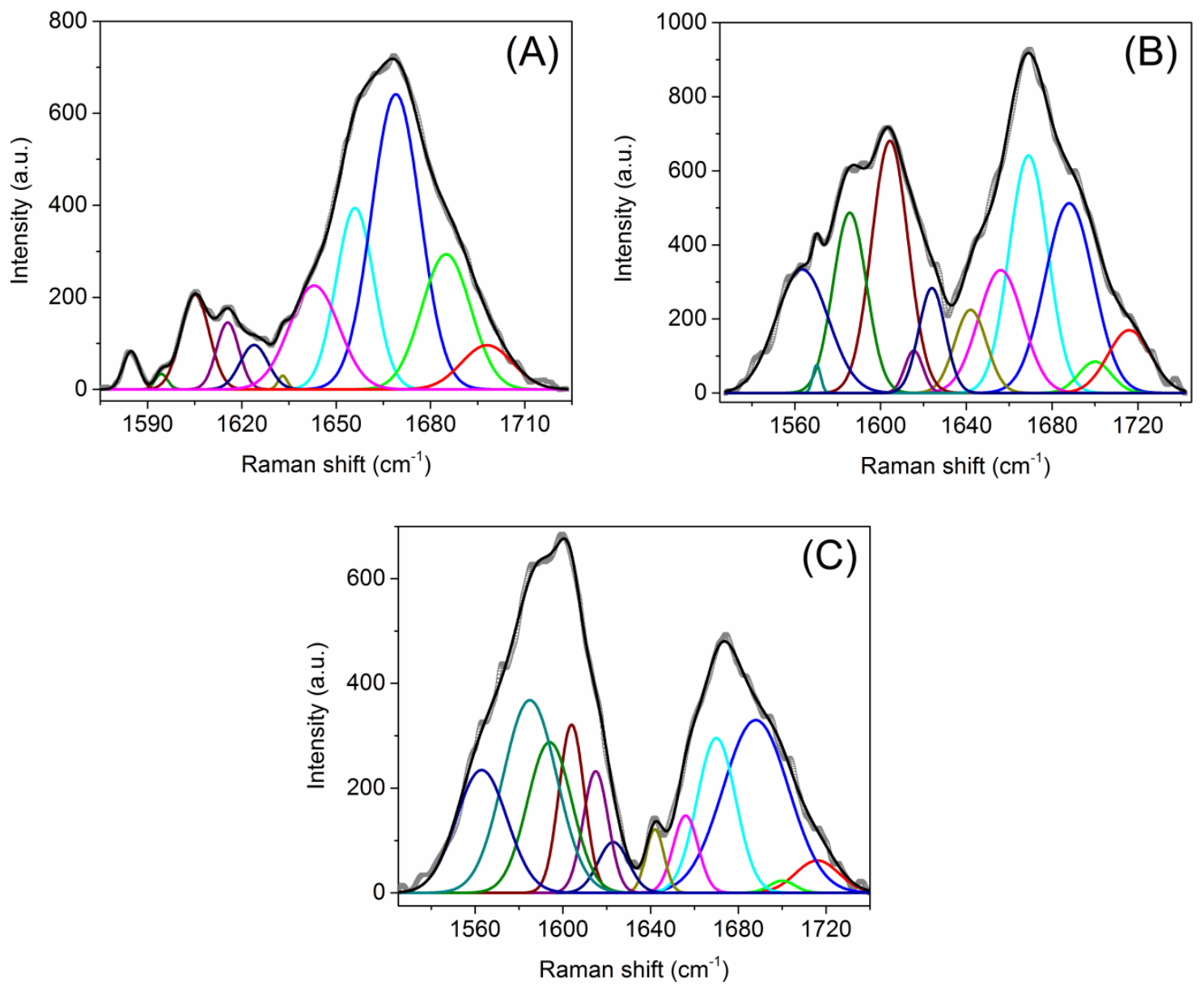

Figure S5. Deconvoluted Raman spectrum of (A) SPI, (B) SPI gel pH7, and (C) SPI gel pH12. 

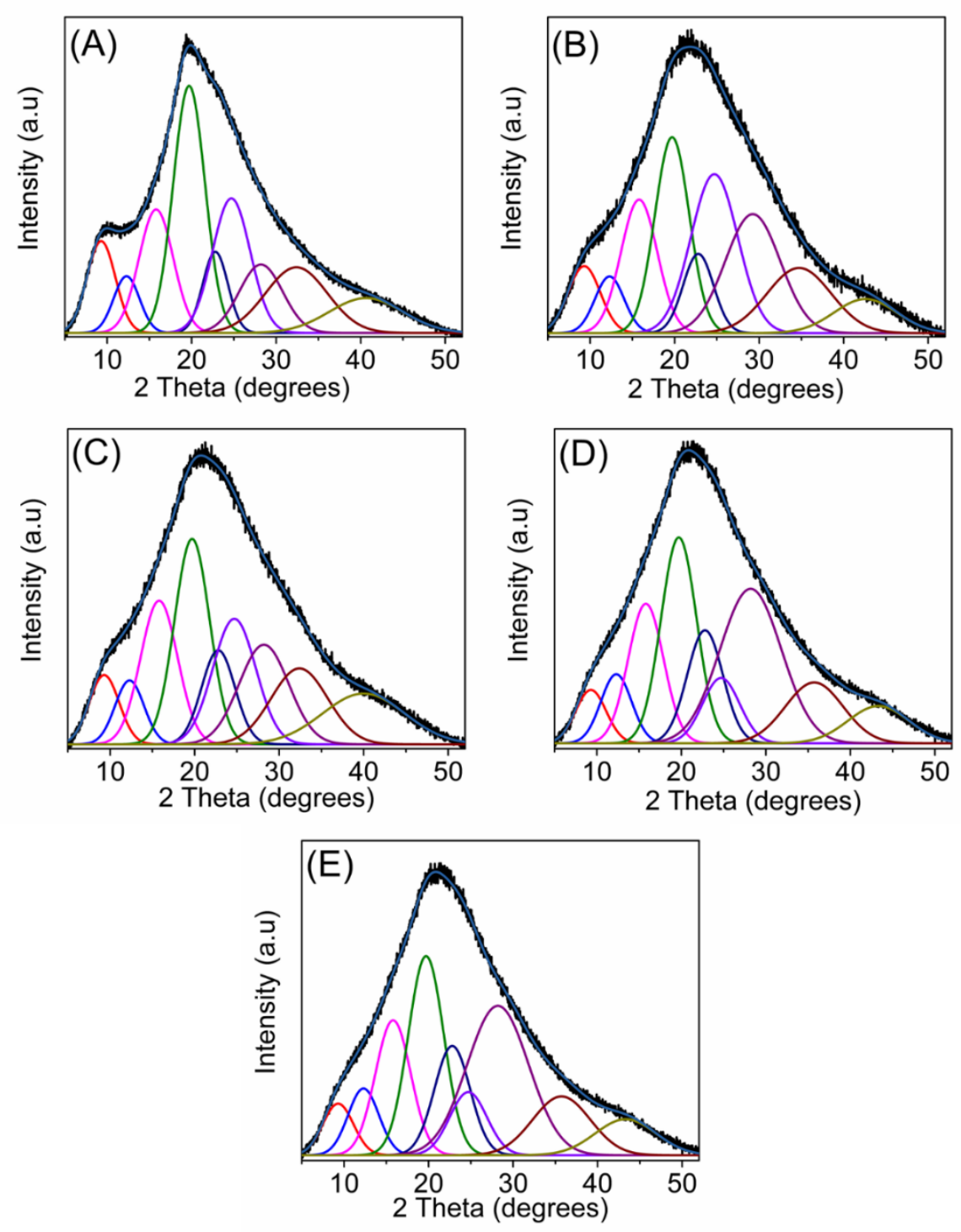

Figure S6. Deconvoluted X-ray diffractogram of (A) SPI gel pH7, (B) SPI/SF (3:1) gel, (C) SPI/SF (1:1) gel, (D) SPI/SF (1: 3) gel and (E) SF gel. 

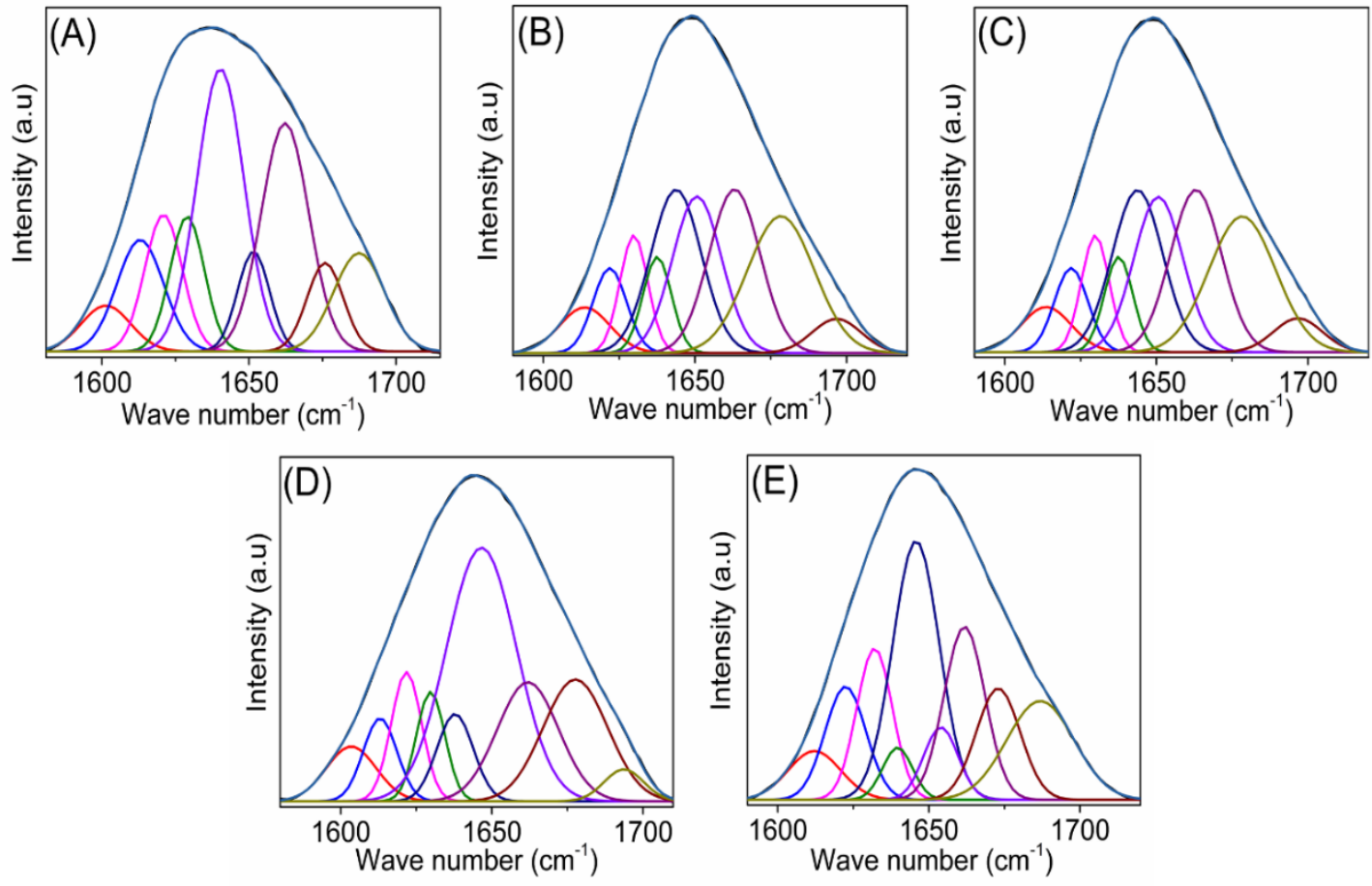

Figure S7. Deconvoluted FTIR spectrum of (A) SPI gel pH7, (B) SPI/SF (3:1) gel, (C) SPI/SF (1:1) gel, (D) SPI/SF (1:3) gel and (E) SF gel.

\section{References:}

(1) Babu, K. M., Silk fibres. In Handbook of Natural Fibres, Kozłowski, R. M., Ed. Woodhead Publishing: 2012, pp 146-170.

(2) Bakarich, S. E.; Panhuis, M. H.; Beirne, S.; Wallace, G. G.; Spinks, G. M., Extrusion printing of ionic-covalent entanglement hydrogels with high toughness. J. Mater. Chem. B 2013, 1 (38), 4939-4946.

(3) Balu, R.; Reeder, S.; Knott, R.; Mata, J.; de Campo, L.; Dutta, N. K.; Choudhury, N. R., Tough photocrosslinked silk fibroin/graphene oxide nanocomposite hydrogels. Langmuir 2018, 34 (31), 9238-9251.

(4) Herrero, A. M.; Jiménez-Colmenero, F.; Carmona, P., Elucidation of structural changes in soy protein isolate upon heating by Raman spectroscopy. Int. J. Food Sci. Tech. 2009, 44 (4), 711-717. 